\title{
STAGS Developments for Residual Strength Analysis Methods for Metallic Fuselage Structures
}

\author{
Richard D. Young ${ }^{1}$ and Cheryl A. Rose ${ }^{2}$ \\ NASA Langley Research Center, Hampton, VA 23681
}

\begin{abstract}
A summary of advances in the Structural Analysis of General Shells (STAGS) finite element code for the residual strength analysis of metallic fuselage structures, that were realized through collaboration between the structures group at NASA Langley, and Dr. Charles Rankin is presented. The majority of the advancements described were made in the 1990's under the NASA Airframe Structural Integrity Program (NASIP). Example results from studies that were conducted using the STAGS code to develop improved understanding of the nonlinear response of cracked fuselage structures subjected to combined loads are presented. An integrated residual strength analysis methodology for metallic structure that models crack growth to predict the effect of cracks on structural integrity is demonstrated.
\end{abstract}

\section{Introduction}

$\mathrm{C}$ ommercial transport are designed with a damage tolerant design philosophy that requires the aircraft to maintain adequate structural integrity in the presence of discrete source damage or fatigue cracks. As economic and market conditions encourage the use of commercial airplanes beyond their original design service life, it is important to be able to predict the fatigue life and residual strength of fuselage structures with cracks. Widespread fatigue damage (WFD) is a significant concern for the aging aircraft fleet because the residual strength of structure with a long crack might be significantly reduced by the existence of adjacent smaller cracks. ${ }^{1}$ The accident of the Aloha aircraft, shown in Fig. 1, made aging aircraft a national priority. The Aloha aircraft accident is an example of WFD, where several short fatigue cracks along a fuselage lap joint linked together and un-zipped an 18-foot-long section of the crown of the fuselage. Another example demonstrating the threat to the structural integrity of aging aircraft is shown in Fig. 2. The aircraft shown in this figure was damaged when a fatigue crack from a manufacturing flaw caused engine failure during takeoff. Uncontained engine debris from the engine penetrated the fuselage, killing two passengers and significantly compromising the structure.

The Aloha aircraft resulted in the launching of NASA and FAA initiatives in aging aircraft. One of the objectives of the NASA Airframe Structural Integrity Program (NASIP) was to develop an integrated computational methodology for predicting the residual strength of a fuselage structure with one or more cracks. The structural response of a stiffened fuselage with long cracks, such as mid-bay cracks or splice joint cracks after multi-site damage (MSD) link-up, is extremely complex, and is influenced by local stress and displacement gradients near the crack, and by the internal load distribution in the shell. Local fuselage out-of-plane skin displacements near a crack that are induced by internal pressure loads can be large compared to the skin thickness, and these displacements can couple with the internal stress resultants in the shell to amplify the magnitudes of the local stress and displacements near the crack. In addition, the stiffness and internal load distributions in a shell with a crack will change as the crack length increases. Finally, for ductile materials such as 2024-T3 aluminum, plasticity effects at the crack tips have to be accounted for in crack growth predictions. All of these complexities must be accurately predicted in order to determine accurately the structural integrity and residual strength of a fuselage shell with damage.

The Structural Analysis of General Shells $\left(\right.$ STAGS) ${ }^{2}$ geometric and material non-linear finite element analysis code is particularly well suited for analyzing complex built-up structures, with the complex geometric and material nonlinear response described above, and was selected as the structural analysis tool to be used in developing the integrated structural integrity analysis methodology. STAGS was originally developed to predict the strength,

\footnotetext{
${ }^{1}$ Project Manager, Aeronautics Research Directorate. NASA LaRC. Senior Member, AIAA.

${ }^{2}$ Senior Aerospace Engineer, Structural Mechanics and Concepts Branch. NASA LaRC. Senior Member, AIAA.
} 
stability, and nonlinear response of nonaxisymmetric or general shells, and includes analysis capability for both geometric and material nonlinear behavior. Complex stiffened shell structures can be modeled to include as many finite elements as required to represent accurately the response of each structural member in the stiffened structure. At the start of the NASIP program the STAGS code, however, did not have capabilities for efficiently conducting crack growth studies and needed extensions to facilitate development of the residual strength analysis methodology.

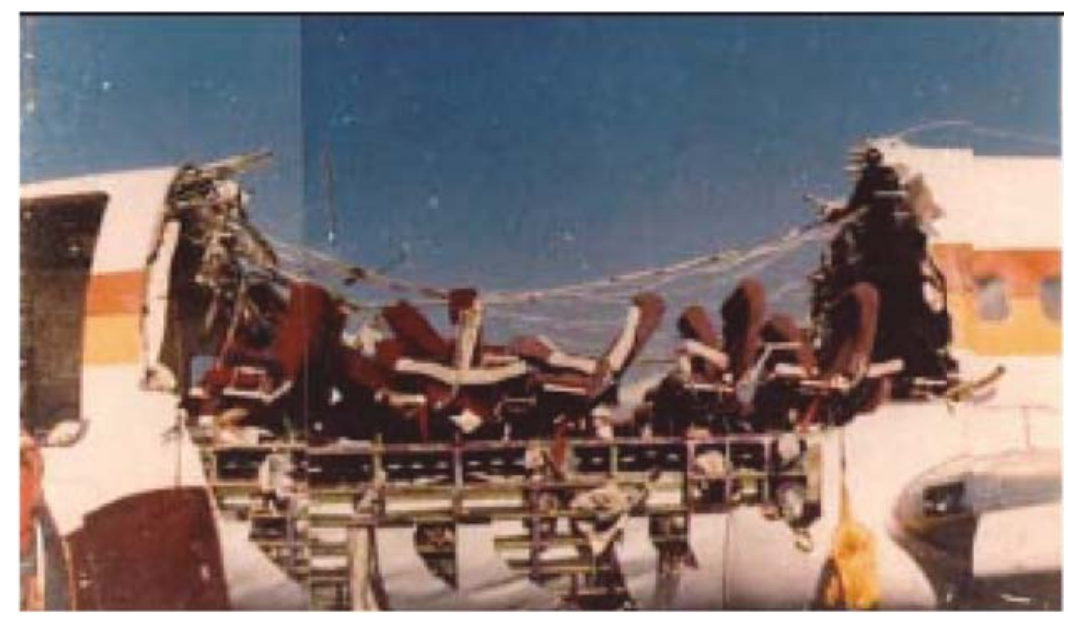

Figure 1. Wide-spread fatigue damage causes in-flight fuselage crown panel separation. Aloha Airlines, Boeing 737, April 28, 1988.

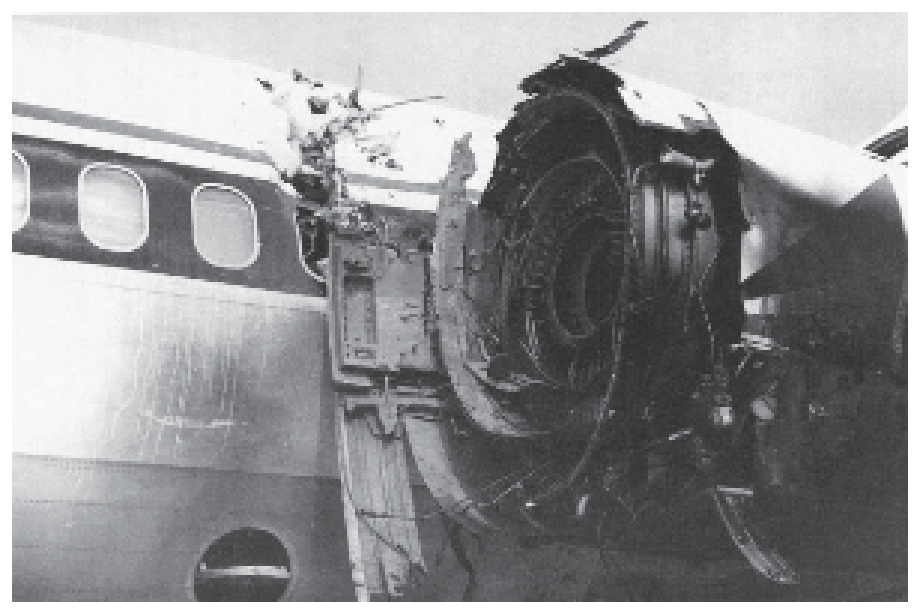

Figure 2. Engine failure during take-off with uncontained debris penetrating fuselage. Delta Airlines, MD-88, July 6, 1996.

The present paper provides a brief summary of the response characteristics of through cracks in fuselage shells described above, and crack analysis features that were added to the STAGS code, through collaboration between NASA Langley Research Center and Dr. Charles Rankin, while at Lockheed Palo Alto Research Laboratory, that enabled advances in residual strength analysis methods for metallic structures. Both self-similar and curvilinear crack growth capability was added, with the topological description of curvilinear crack growth provided by coupling STAGS with the automatic adaptive remeshing capability of FRANC3D., Example problems are then presented to demostrate and validate the residual strength analysis capabilities that were developed and implemented in STAGS. The examples are drawn primarily from research activities conducted by the authors during the NASIP. 


\section{Response Characteristics of Stiffened Fuselage Shells}

The stresses in a thin-walled infinitely long cylindrical shell subjected to internal pressure loading are given by

$$
\sigma_{x}=\frac{p R}{2 t} ; \quad \sigma_{y}=\frac{p R}{t}
$$

where $p$ is the internal pressure, $R$ is the shell radius and $t$ is the shell wall thickness. In the case of an unstiffened cylindrical shell, the circumferential or hoop stress, $\sigma_{y}$ is twice as large as the longitudinal stress, $\sigma_{x}$. In fuselage shells, where stiffeners are present, the stress state is not uniform, and the stresses are reduced compared to those in an unstiffened shell. The circumferential stress reduction in the fuselage skin, however, is marginal, except close to stiffener and frame elements, where the reduction is more significant. ${ }^{5}$ Therefore, for internal pressure loading, the stress state in the majority of a fuselage shell is dominated by the circumferential stress, and cracks in the shell will grow longitudinally rather than circumferentially.

A crack in thin-walled shell subjected to internal pressure loading with circumferential stress, $\sigma_{y}$, deforms differently than a crack in a flat plate loaded equivalently in tension normal to the crack. In a cracked shell under internal pressure, the crack opens up in a plane tangential to the shell, and also deforms radially outward, or bulges, where, in a plate, the crack deforms in-plane only. ${ }^{6-8}$ These out-of-plane displacements in the neighborhood of a crack in a shell are caused by curvature induced coupling between the membrane and bending displacements in a shell, and increase the crack opening and the crack-tip stress intensity factor compared to those of a cracked plate with the same crack geometry and far-field loading. The bulging factor, $\beta$, accounts for the fundamental difference in behavior of a crack in a curved shell compared to the behavior of a crack in a curved plate, by amplifying the flatplate stress-intensity factor. The bulging factor is defined as the ratio of the stress intensity factor $K_{s}$ in a shell with a crack, to the stress intensity factor $K_{p}$ in a flat plate of the same material, thickness, crack length, and in-plane remote stress, $\sigma_{y}$, acting perpendicular to the crack line:

$$
\beta=\frac{K_{s}}{K_{p}}
$$

Many studies have been conducted to characterize bulging cracks, and both analytical ${ }^{9-16}$ and empirical formulas $^{17-22}$ for the bulging factor have been developed. Analytical expressions for the bulging factor in shells were developed using formulations based on linear shallow shell theory. These analytical expressions depend on the shell curvature parameter, $\lambda$, where, for an isotropic shell, $\lambda$ is defined as:

$$
\lambda=\frac{a}{\sqrt{R t}} \sqrt[4]{12\left(1-v^{2}\right)}
$$

and:

$$
\begin{aligned}
& v=\text { Poisson's ratio } \\
& a=\text { half crack length } \\
& R=\text { radius of the shell } \\
& t=\text { thickness of the shell }
\end{aligned}
$$

The analytical bulging factors based on linear shallow shell theory tend to overestimate the physical bulging effect, particularly for longitudinal cracks, unless the cracks are very short, or the applied load is very small, so that geometric nonlinear effects are not significant. The significance of the geometric nonlinear effects was demonstrated by Riks et $a 1^{6}$ in the first analysis conducted in STAGS that considered a shell with a crack. These studies demonstrated that for longer cracks or higher loads, tensile membrane stresses develop along the crack edges as the crack bulges. These tensile stresses increase the resistance to additional crack bulging and crack opening, and result in a reduction in the bulging factor compared to those obtained from linear shallow shell theory. ${ }^{21-22}$ The resistance to additional bulging is particularly significant if the axial stress, $\sigma_{x}$ in the shell is tensile, as is the case for internal pressure loading. In other loading cases that represent different flight conditions, the axial stress may be 
compressive and the beneficial influence of the membrane tensile stresses developing along the crack edges is reduced or possibly reversed.

Early work conducted in the NASIP program focused on developing further the understanding of the effects of combined loads and geometric nonlinearity on the response of complex built-up fuselage structure. ${ }^{23-25}$ Computational studies of the nonlinear response of stiffened shells with long cracks were conducted using relatively coarse models of a stiffened shell to obtain qualitative information on the effects of crack location, crack orientation, and various combinations of internal pressure and mechanical loads on the response characteristics. Results from a typical early study are shown in Fig. 3. In this case, a numerical study was conducted for a full-barrel fuselage with a longitudinal crack in the crown, and subjected to internal pressure loading, and internal pressure plus up-bending and down-bending moments. The crack edges are loaded in axial compression when an up-bending moment is applied and in axial tension when a down-bending moment is applied. The results shown in Fig. 3 indicate that the local crack deformations are symmetric, so fracture is governed by the symmetric crack-opening stress-intensity factor, $\mathrm{K}_{\mathrm{I}}$. In addition, the results indicate that the symmetric crack-opening stress-intensity factor is the largest for the up-bending moment case, where there is local axial compression along the crack edges, and is the smallest for the down-bending moment case. These results demonstrate sensitivity to combined loads and also represent a geometrically nonlinear response, as linear analyses do not indicate such a combined load effect.

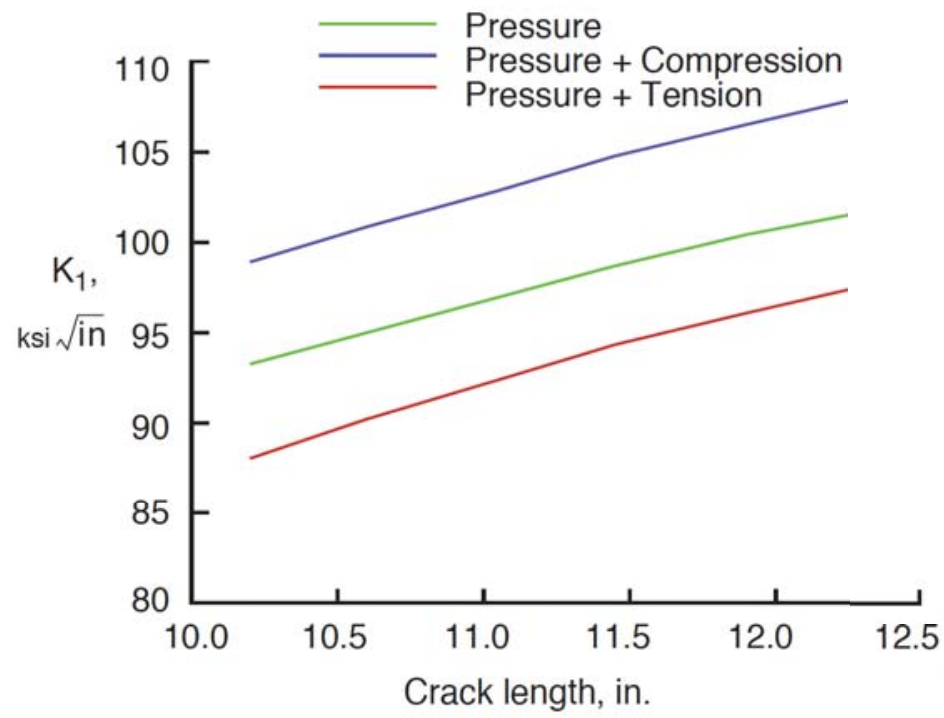

Crack length, in.

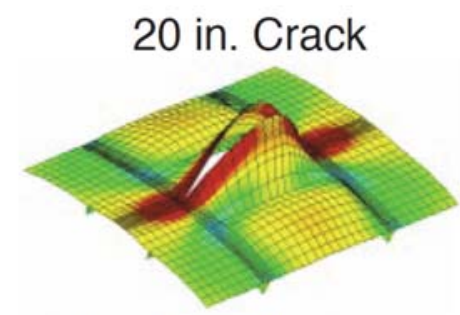

Internal Pressure Loading

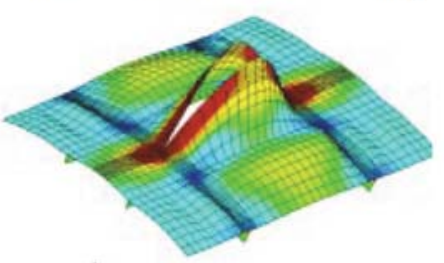

Internal Pressure + Up

Bending Moment Loading

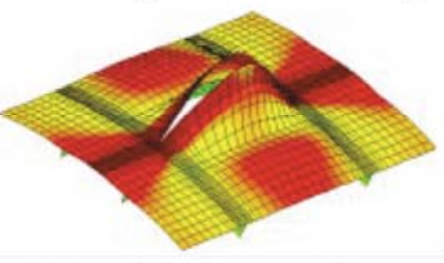

Internal Pressure + Down

Bending Moment Loading

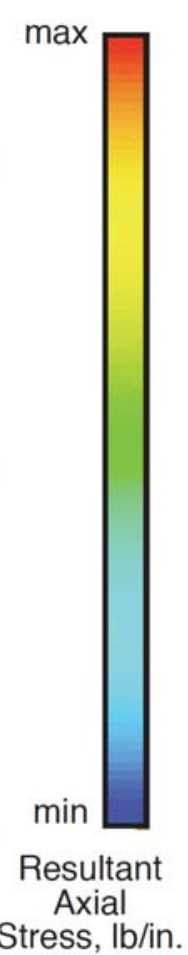

Stress, Ib/in.

Figure 3. Crack-opening stress-intensity factor for a longitudinal crack in a fuselage shell subjected to internal pressure loading, and internal pressure loading plus an up-bending and a down-bending moment.

Additional preliminary studies were conducted to determine the effect of crack location within the fuselage structure, and the effect of shear and torsion fuselage loadings on the local crack deformations and stress-intensity factors. Results from these studies indicated that torsion loads could cause an increase in the crack-shearing stressintensity associated with a crack. Results also showed that the crack-growth trajectory could be influenced by the crack location and the loading condition. A typical result from a study of the effects of loading condition and crack location on crack growth trajectories is shown in Fig. 4. Crack growth trajectories are shown in Fig. 4 for three longitudinal crack locations and loading conditions. The crack is either located midway between two stringers or 1.2 inches from a stringer. The crack-growth trajectory for a crack located midway between two stringers in a panel 
that is subjected to internal pressure, up-bending and vertical shear loads is shown in Fig. 4a. The crack-growth trajectory for this case is self-similar due to the symmetry of the loading and the geometry. The crack-growth trajectory for a crack located $1.2 \mathrm{in}$. from a stringer in a panel that is subjected to internal pressure, up-bending and vertical shear loads is shown in Fig. 4b. In this case the crack-growth trajectory is non-self-similar due to the nonsymmetry of the geometry. The crack growth trajectory for a crack that is located midway between two stringers in a panel that is subjected to internal pressure and torsion loads is shown in Fig. 4c. The crack-growth trajectory for this case is non-self-similar due to the non-symmetry of the loading condition.

These and additional preliminary results demonstrated important aspects of the response of a long crack in a stiffened fuselage shell and several general conclusions were drawn from these initial studies. First, long cracks can change the internal load distribution in a stiffened shell. Secondly, the pressure only loading case, which is typically used as the critical design condition in practice, can result in unconservative predictions for the fuselage shell residual strength. Therefore, the effects of combined loads must be considered. Third, the local shell response is geometrically nonlinear, as evidenced by the effect of combined loads on the crack-tip stress-intensity. Local displacements near a crack can be large compared to the fuselage thickness, and these displacements can couple with internal stresses resultants in the shell to amplify magnitudes of the local stresses and displacements near the crack. Fourth, the crack behavior is strongly influenced by structural stiffening elements. Furthermore, fracture of fuselage structures made from ductile aluminum alloys exhibit a large degree of plasticity near the crack tip. Thus, a fracture criterion that accounts for elastic-plastic material nonlinearity would also be required. All of these complexities are present in fuselage shell structure with damage and must be addressed in residual-strength analysis methods for fuselage structure.

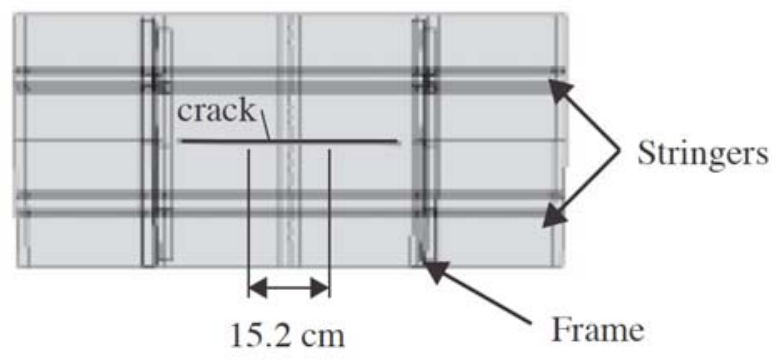

(a) 40.6-cm-long crack trajectory for internal pressure, up-bending and vertical shear loads with crack midway between stringers.

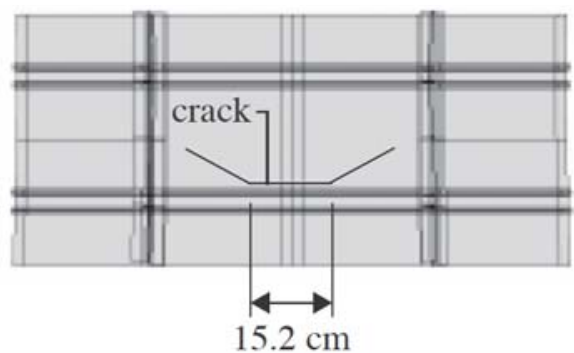

(b) 40.6-cm-long crack trajectory for internal pressure, up-bending and vertical shear loads with crack $3.1 \mathrm{~cm}$ from a stringer.

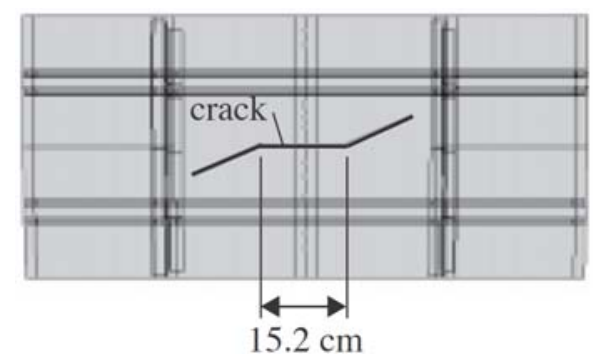

(c) 40.6-cm-long crack trajectory for internal pressure and torsion loads with crack initially midway between stringers.

Figure 4. Effect of fuselage loading condition and crack location on crack growth trajectories.

\section{Features of the STAGS Code for Residual Strength Analysis of Metallic Fuselage Structure}

The STAGS (Structural Analysis of General Shells) finite element code was originally developed by Lockheed Palo Alto Research Laboratory to predict the strength, stability and nonlinear response of non-axisymmetric or general shells. The effects of both geometric and material nonlinearities are included in the analysis. The code uses both the modified and full Newton methods for its nonlinear solution algorithms, and accounts for large rotations in 
a shell by using a co-rotational algorithm at the element level. STAGS has static and transient analysis capabilities that can be used to predict local instabilities and modal interactions that occur due to destabilizing mechanical loads, such as an applied compression or shear load. The Riks pseudo arc-length path following method ${ }^{26,27}$ is used to continue a solution past the limit points of a nonlinear response. With this strategy, the incrementally applied loading parameter is replaced by an arc-length along the solution path, which is then used as an independent loading parameter. The program as a function of the solution behavior automatically adjusts the arc-length increments.

The finite element library includes non-linear beam, plate and shell elements, that can be used in combinations to represent complex built-up fuselage structures. The plate and shell elements follow plane stress assumptions and are formulated in a corotational framework, ${ }^{28,29}$ to render solutions that are valid for arbitrary displacements and moderate rotations, as long as the strains remain small. STAGS is also equipped with special features for representing fasteners between structural elements and contact between built-up components that are not continuously connected. Models of sections of a fuselage can be built with these elements allowing a large degree of detail.

The White-Besseling mechanical sublayer distortional energy plasticity theory ${ }^{30}$ is used to describe the crack-tip plasticity. In this model the state of stress at a material point of the body under investigation is subdivided into components called fractions, and each fraction has its own yield function and flow rule. In STAGS the individual fractions are treated as elastic-perfectly plastic. ${ }^{1}$ The number of fractions used to represent an experimentally determined material stress-strain curve is defined by the user. The discrete form of the stress-strain curve is used to determine the parameters for each fraction. The White-Besseling model is able to represent cyclic loading and unloading.

STAGS also has a unique, computationally robust capability for performing crack-propagation analyses, and for determining the effects of the crack growth on load redistribution in the structure. Many of the crack-growth capabilities that currently exist within STAGS were implemented by Dr. Charles Rankin and his co-workers in the 1990s, in collaboration with Dr. James H. Starnes and the structures group at NASA Langley Research Center, during the NASA Airframe Structural Integrity Program (NASIP). Both self-similar and curvilinear crack growth can be represented. In the case of self-similar crack growth, the crack path is defined a-priori. The initial crack definition and crack propagation is constrained to occur along a pre-determined path, which corresponds to element boundaries. Along this path, double nodes (master and slave node) occupying a single position in space and belonging to two sets of elements on either side of the crack path are defined. For curvilinear crack growth, where the crack path is not known a-priori, crack turning criteria and nonlinear adaptive mesh capabilities are required to determine when a crack will turn, the direction of crack growth, and the necessary finite element model changes as the crack propagates. A unique capability was developed for curvilinear crack growth prediction that integrated the fracture topology modeling capabilities of FRANC3D ${ }^{3,4}$ with the general shell analysis capabilities of STAGS into an integrated FRANC3D - STAGS analysis procedure.

Crack growth simulation in a shell is performed in STAGS using a nodal release method and a modified pathfollowing method as described in Ref. 31. The applied load on a structure is increased until crack extension is indicated based upon a crack-tip fracture criterion. When a crack is to be extended, the forces necessary to hold the current crack-tip nodes together are calculated. Then, with the load held constant, the crack is extended by releasing the nodal compatibility condition at the crack tip, applying the equivalent crack-tip forces, and then releasing these forces to establish a new equilibrium state, which corresponds to the longer crack. The changes in the stiffness matrix and the internal load distribution that occur during crack growth are accounted for in the analysis, and the nonlinear coupling between internal forces and in-plane and out-of-plane displacement gradients that occurs in a shell are properly represented.

Currently the critical Crack-Tip Opening Angle $\left(\mathrm{CTOA}_{\mathrm{cr}}\right)$ criterion is the only fracture criterion implemented in STAGS. The $\mathrm{CTOA}_{\mathrm{cr}}$ fracture criterion is described in Refs. 32 - 34, and is applicable when conducting an elasticplastic fracture analysis. The CTOA, defined schematically in Fig. 5 is defined as the angle made by the upper crack surface, the crack tip, and the lower crack surface, evaluated at a fixed distance from the moving crack tip. The criterion assumes that stable crack growth will occur when the angle reaches a critical value, CTOA $\mathrm{C}_{\mathrm{cr}}$, and that the $\mathrm{CTOA}_{\mathrm{cr}}$ will remain constant as the crack extends. These assumptions are supported by experimental studies and numerical elastic-plastic finite element analyses that have shown that, in several metals, the CTOA is essentially constant after some initial crack growth. The value of the critical angle is dependent on the sheet material, the sheet thickness and the crack orientation. The critical angle for a particular material and thickness can be obtained by numerically simulating the fracture behavior of a laboratory specimen using an elastic-plastic finite element analysis, and determining the angle that best describes the experimentally observed fracture behavior. The determined angle can then be used to predict the fracture behavior of different structural configurations. In the numerical simulation, a characteristic distance behind the crack tip is defined for evaluating the angle. The crack 
opening displacements behind the crack are monitored and the crack is advanced by one element length when the opening angle evaluated at the characteristic distance reaches the critical value.

When a crack is present in a structure, the plane stress assumptions of the shell elements are valid for the majority of the structure, but not in the immediate vicinity of the crack-tips where the plastic zone develops. Within this zone the state of stress is three-dimensional, and studies have shown that incorporating three-dimensional constraint effects that develop in the plastic zone in an elastic-plastic crack-growth analysis is required to prevent dependence of residual strength analysis results on structural dimensions. ${ }^{35,36}$ To eliminate this dependence, the three-dimensional constraint effects are approximated in a two-dimensional model by incorporating a "core" of plane-strain elements of height $h_{c}$, as shown in Fig. 5, on each side of the crack line ${ }^{1}$ or similarly by introducing volume elements in the boundary layer of the crack line. Standard eight-noded isoparametric brick elements in STAGS are used when volume elements are used in the crack-line boundary layer, and are connected to the surrounding shell elements using procedures that are described in Ref. 37.

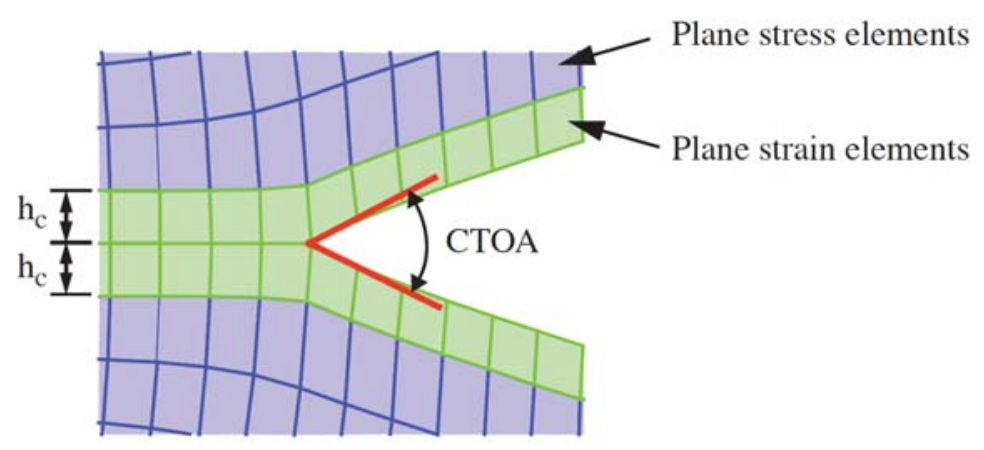

Figure 5. Schematic for fracture parameters, $\mathrm{CTOA}_{\mathrm{cr}}$ and $\mathbf{h}_{\mathrm{c}}$.

Although not used in STAGS as a criterion for crack growth, stress intensity factors are routinely calculated at any step in a crack growth process and can be used to characterize the crack front behavior. The stress-intensity factors are extracted from the strain-energy-release-rate calculated during crack extension. The total stress intensity factor is calculated from the total strain-energy-release rate, $G$ :

$$
K_{T}=\sqrt{E G}
$$

The strain-energy-release terms are computed in STAGS, from a nonlinear equilibrium state, using the modified crack closure integral technique. ${ }^{38}$ This integration method makes it possible to distinguish between the various modes of loading on a crack, enabling the calculation of independent stress intensity factors for each mode. A set of four stress-intensity factors proposed by Hui and Zehnder ${ }^{39}$ are calculated. The modes of loading and their corresponding stress-intensity factors are illustrated in Fig. 6. These stress-intensity factors can be used to account for the in-plane and out-of-plane modes of loading experienced by a through crack in a fuselage structure. In Hui and Zehnder's model the mechanical behavior near the crack tip is idealized using Kirchoff plate theory to account for the bending loads, and two-dimensional elasticity to account for the in-plane loads. The stress-intensity factors based on Kirchoff plate theory are denoted by $k_{1}$ and $k_{2}$, and the stress-intensity factors based on two-dimensional elasticity are denoted by $K_{I}$ and $K_{I I}$. The symmetric stress-intensity factors, $K_{I}$ and $k_{l}$, correspond to in-plane tensile loading and out-of-plane bending loading, respectively. The anti-symmetric stress-intensity factors, $K_{I I}$ and $k_{2}$, correspond to in-plane shearing stresses, and out-of-plane shear forces and twisting moments, respectively.

\section{Example Problems}

\section{A. Nonlinear Bulging Factors ${ }^{40-42}$}

A geometrically nonlinear finite element parametric study was conducted to determine curvature correction factors or "bulging factors" that account for increased crack-tip stresses due to curvature for longitudinal and circumferential cracks in unstiffened cylindrical shells subjected to combined loads. The objective of this study was to establish a solid understanding of the effects of curvature, combined loads, and geometric nonlinearity on linear 
elastic fracture parameters for unstiffened shell structures. The study was motivated by the traditional approach to residual strength analyses and damage tolerant design that relied primarily on geometrically linear analyses and fracture analyses based on linear elastic fracture mechanics. Linear elastic fracture mechanics suggests that the crack-tip stress intensity factor is an indicator of the likelihood of fracture. The conventional engineering approach

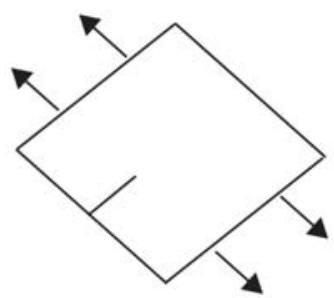

Symmetric membrane loading, $K_{I}$

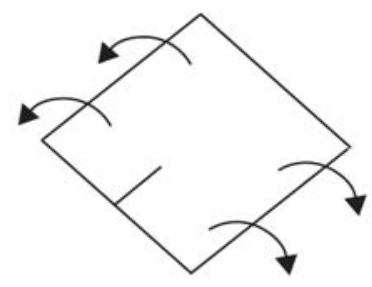

Symmetric

bending loading, $k_{1}$

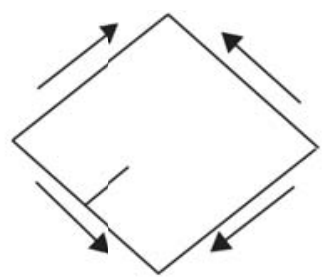

Anti-symmetric membrane loading, $K_{I I}$

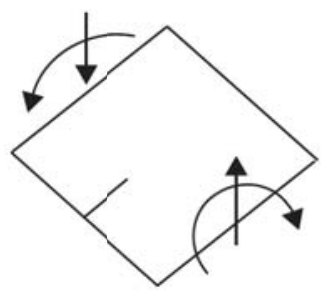

Anti-symmetric bending loading, $k_{2}$

Figure 6. The four stress-intensity factors and corresponding loading modes for a through crack in a thin plate. ${ }^{16}$

used in design practice was to predict the crack-tip stress intensity factors for a crack in a fuselage shell by applying the so-called "bulging factor," as defined in Eq. (2), in combination with additional design factors that account for stiffener elements, to the stress intensity factor for a flat plate subjected to similar loading conditions.

As discussed previously, analytical bulging factors derived based on linear shallow shell theory overestimate the physical bulging effect, unless the cracks are very short, or the applied load is very small, so that geometric nonlinear effects are not significant. Empirical formulas, which attempt to account for the nonlinear character of the bulging response, have been developed for determining bulging factors in shells with longitudinal cracks. ${ }^{17-22}$ These empirical formulas were developed for specific materials, geometries and loading conditions, and thus, the formulas are valid for limited applications. A more general investigation of the geometrically nonlinear response of pressurized cylindrical shells with longitudinal cracks was conducted by Budiman and Lagace. ${ }^{43,44}$ They demonstrated that the nonlinear response of cylindrical shells with longitudinal cracks, subjected to internal pressure loading, can be characterized by two nondimensional parameters: the shell curvature parameter, $\lambda$, as defined in Eq. (3); and a loading parameter, $\eta$, which depends on the applied internal pressure, material properties, and shell geometry. Research conducted by Rose, Young, and Starnes ${ }^{38-40}$ extended the study conducted by Budiman and Lagace by investigating the effects of combined loads and geometrically nonlinear response on the bulging factor of long longitudinal and circumferential cracks in unstiffened, pressurized cylindrical shells. A comprehensive numerical parametric study of the geometrically nonlinear response of unstiffened aluminum shells with centrally located longitudinal and circumferential cracks subjected to combined internal pressure and mechanical loads was conducted using the STAGS nonlinear finite element analysis code. Major results of the study were contour plots for the bulging factor, $\beta$, and empirical expressions for estimating the bulging factor for longitudinal and circumferential cracks in both the linear and nonlinear region of the response. Contour plots of the bulging factor were presented in terms of three nondimensional parameters: the curvature parameter, $\lambda$, a pressure loading parameter, $\eta$, defined as: 


$$
\eta=\sqrt{\frac{\sigma_{y} R}{E t}}\left(\sqrt[4]{12\left(1-v^{2}\right)}\right)
$$

where $\sigma_{y}$ is the far-field circumferential stress, and the biaxial loading parameter,

$$
\chi=\frac{\sigma_{x}}{\sigma_{y}} .
$$

\section{Longitudinal Crack}

Typical results obtained in the study for the bulging factor for a longitudinal crack in a cylindrical shell, $\beta^{L}$, as a function of the shell curvature parameter, $\lambda$, and the pressure loading parameter, $\eta$, are presented as contour plots in Fig. 7. Bulging factors for $\chi=0.0,0.5,1.5$, and 6.0, are shown in Fig. 7a, 7b, 7c, and 7d, respectively. A biaxial loading parameter $\chi=0.5$ corresponds to the internal pressure only loading condition. The solid lines in the figure are contour lines, or lines through points with a common value of the bulging factor. There are some general trends indicated by the contour plots. For a given value of $\chi$, the bulging factors monotonically increase with increasing values of $\lambda$, and generally decrease with increasing values of $\eta$. In each contour plot, the bulging factor for very small values of $\eta$, i.e., for locations near the $\lambda$-axis, corresponds to the linear bulging factor, as reported by Erdogan and Kibler, ${ }^{14}$ and does not vary with changes in $\chi$. For small values of $\eta$, the contour lines are nearly perpendicular to the $\lambda$-axis, indicating that the bulging factor for small values of $\eta$ is primarily a function of $\lambda$ only and can be approximated by the linear bulging factor, $\beta_{\text {lin }}^{L}$. The unshaded areas of the contour plots in Fig. 7 indicate the linear region of the response where the difference between $\beta^{L}$ and $\beta_{\text {lin }}^{L}$ is less than $10 \%$. For higher values of $\eta$, the bending deformations become sufficiently large and cause nonlinear membrane stiffening. The bulging factors decrease with increasing $\eta$, and the contour lines bend to the right and asymptotically approach lines which extend radially from the origin. The shaded areas of the contour plots in Fig. 7 indicate the nonlinear region of the response where the difference between $\beta^{L}$ and $\beta_{\text {lin }}^{L}$ is greater than $10 \%$. The largest differences between $\beta^{L}$ and $\beta_{\text {lin }}^{L}$ occur when $\lambda$ and $\eta$ are both large, where $\beta_{\text {lin }}^{L}$ overpredicts $\beta^{L}$ by $45 \%$ when $\chi=0$, and by $400 \%$ when $\chi=6$. Comparison of the contour plots for different values of $\chi$ indicates that increasing the biaxial loading parameter promotes tensile membrane behavior, causing the contour lines to bend to the right at lower values of $\eta$, thus reducing the size of the linear response region.

\section{Circumferential Crack}

Results obtained for a circumferential crack demonstrated that the bulging factor for cylindrical shells with circumferential cracks, $\beta^{C}$, has a mild dependence on the biaxial loading parameter. The bulging factors for $\chi=0.5$ are a good estimate for $0.25<\chi<6$, and the largest discrepancies are conservative. Thus, the circumferential bulging factor is characterized for $\chi=0.5$. The bulging factor results from the STAGS analyses of cylindrical shells with circumferential cracks, $\beta^{C}$, are presented as a function of the shell curvature parameter, $\lambda$, and the pressure loading parameter, $\eta$, in Fig. 8. The contour plot of the bulging factors for the circumferential crack with $\chi=0.5$ in Fig. 8 is similar to the contour plot of the bulging factors for the longitudinal crack with $\chi=0.5$ shown previously in Fig. 7(b), and indicates that the bulging factors monotonically increase with increasing values of $\lambda$, and monotonically decrease with increasing values of $\eta$. The primary differences between the bulging factor contour plots for the two crack orientations are that the bulging factor for the circumferential crack is smaller in amplitude, and the contour lines are concentrated nearer to the abscissa of the plot. The contour lines are perpendicular to the $\lambda$-axis for very small loads, but the contours bend to the right almost immediately as $\eta$ is increased, and asymptotically approach lines which extend radially from the origin. The shaded area of the contour plot in Fig. 8 signifies the nonlinear region of the response where the difference between $\beta^{C}$ and $\beta_{\text {lin }}^{C}$ is greater than $10 \%$. This shaded region is closer to the $\lambda$ - axis than it was for the longitudinal crack with $\chi=0.5$, indicating that the transition from the linear bending response to the nonlinear membrane response occurs at smaller values of load for a shell with a circumferential crack than for a shell with a longitudinal crack. The largest differences between $\beta^{C}$ and $\beta_{\text {lin }}^{C}$ occur when $\lambda$ and $\eta$ are both large, which results in $\beta_{\text {lin }}^{C}$ overpredicting $\beta^{C}$ by $100 \%$. 


\section{Summary Remarks}

The results presented in this study demonstrated the ranges of the shell curvature and loading parameters for which the effects of geometric nonlinearity are significant, and showed the effect of biaxial loads on the value of the bulging factor. The primary outcome of this research was accurate nondimensional representation of a complex nonlinear response phenomena, that accounts for combined load effects, and presents a direct improvement to current design methodology for damage tolerance of curved shell structures. The results illustrated that for longitudinal and circumferential cracks, the linear bulging factor is generally overconservative, and using the linear factor may result in designs that are significantly overweight. For circumferential cracks, the bulging factor is insensitive to biaxial loads. For longitudinal cracks, the nonlinear bulging factor is a function of biaxial loading, and designing with the nonlinear result for the pressure-only case is unconservative if the actual loading has axial compression, i.e., $\chi<0.5$.

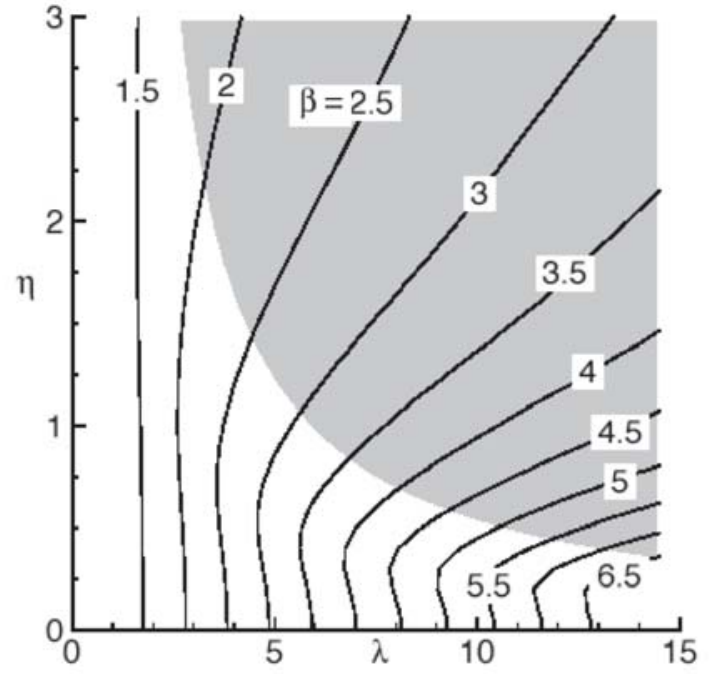

(a) $\chi=0.0$

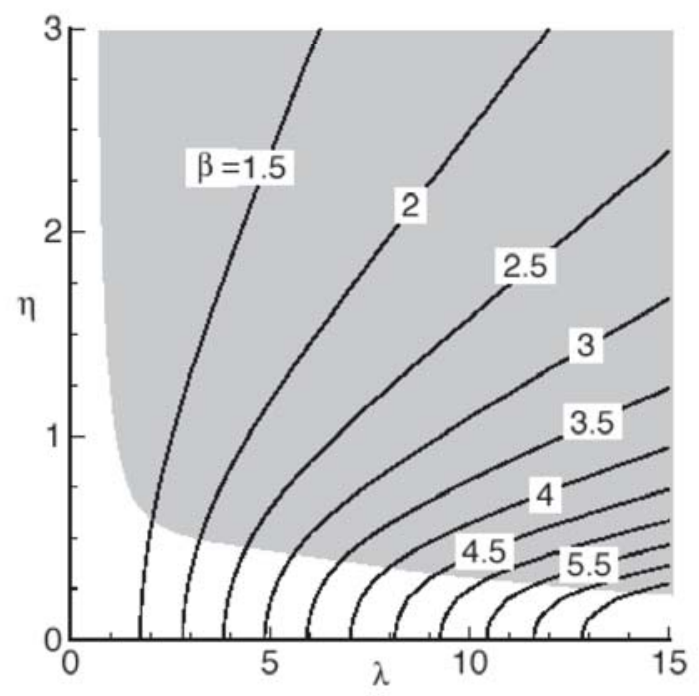

(c) $\chi=1.5$

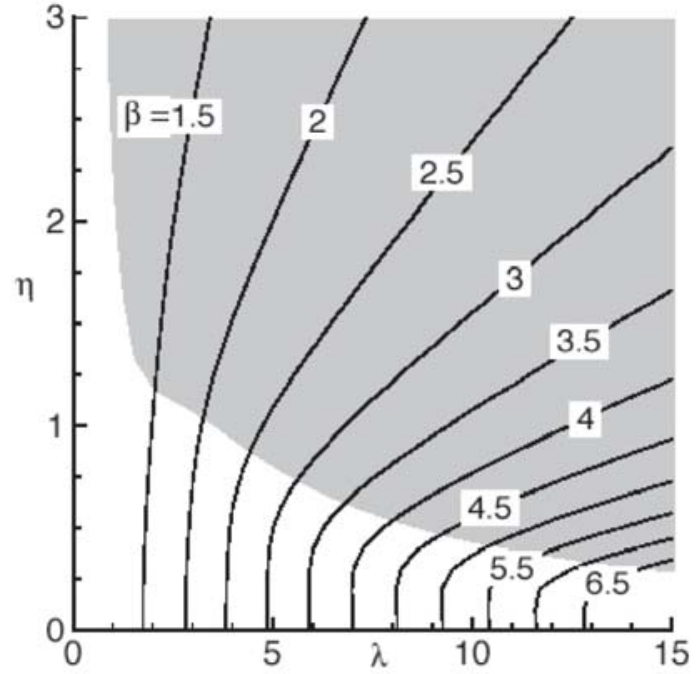

(b) $\chi=0.5$

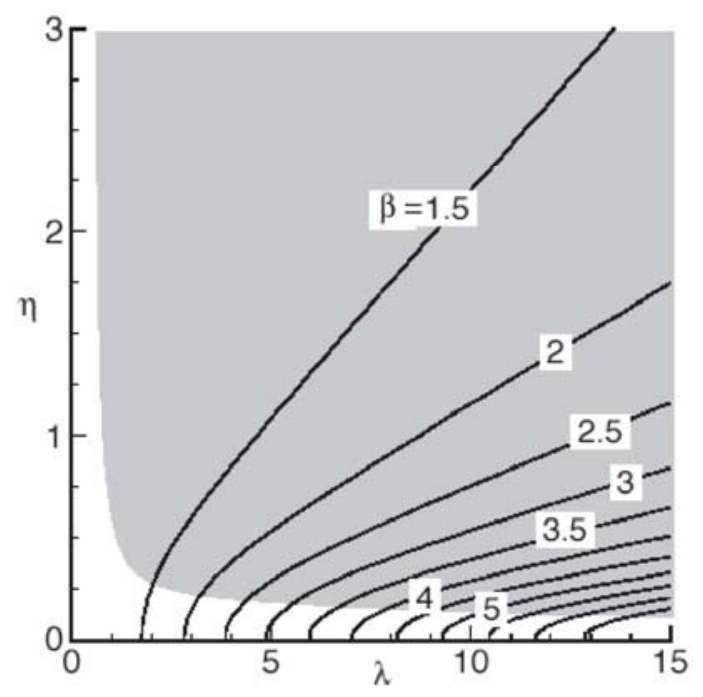

(d) $\chi=6.0$

Figure. 7 Contour plot of the bulging factor for a longitudinal crack, $\beta^{\mathrm{L}}$, from STAGS analyses, and the linear (unshaded) region of the bulging factor response, as a function of the shell curvature parameter, $\lambda$, and the pressure loading parameter, $\eta$, for several values of the biaxial loading parameter, $\chi$. 


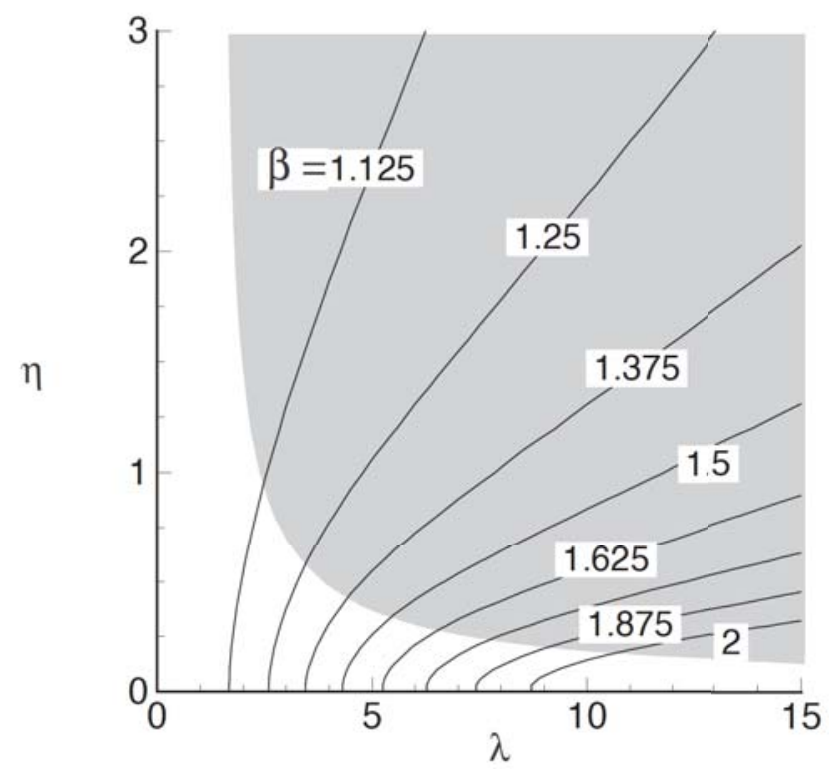

Figure 8. Contour plot of the bulging factor for a circumferential crack, $\beta^{C}$, from STAGS analyses, and the linear (unshaded) region of the bulging factor response, as a function of the shell curvature parameter, $\lambda$, and the pressure loading parameter, $\eta$.

\section{B. Skin, Stringer, and Fastener Loads in Buckled Fuselage Panels ${ }^{45}$}

The objective of the study described in Ref. 45 was to extend previous efforts in modeling and understanding the response of unstiffened shells subjected to internal pressure and mechanical loads to stiffened structure including detailed modeling of stringer and fastener parameters. A numerical study was conducted using the STAGS code to assess the effect of skin buckling on the internal load distribution in a pristine stiffened fuselage panel, and in a stiffened fuselage panel with longitudinal cracks. In addition, the impact of changes in the internal loads on the fatigue life and residual strength of a fuselage panel were assessed. Geometrically nonlinear response was considered, and the response was simplified by considering linear material behavior and examining linear elastic fracture parameters.

The structural configuration considered in this study is shown in Fig. 9, and is a generic narrow-body fuselage panel. It is constructed entirely of 2024-T3 aluminum alloy, with a 74-in. skin radius, a 0.040-in. skin thickness, Zstringers with an 8-in spacing, and Z-frames with a 20-in. spacing. A finite element model of the stiffened fuselage panel with two frame-to-frame longitudinal skin bays and five circumferential stringer bays is shown in Fig. 9. The origin of the $(\mathrm{x}, \mathrm{y})$ coordinate system shown in Fig. 9 is located on the center stringer, and midway between the frames. The model was defined to include one half of a skin-bay beyond the last stiffening member on each edge of the panel. The loading condition for the fuselage panel consists of an applied internal pressure, $p$ (which generates a circumferential stress resultant reaction, $N_{y}$ ), and an axial stress resultant, $N_{x}$, which is the sum of the bulkhead pressure load, and an applied mechanical load. The stress resultants, $N_{x}$ and $N_{y}$, represent the average load in pounds per inch along the longitudinal and circumferential edges of the panel, respectively. A biaxial loading ratio, $\chi$, is defined as the ratio of the axial load to the circumferential load, $\chi=N_{x} / N_{y}$. A biaxial loading ratio $\chi=0.5$ corresponds to the internal-pressure-only loading condition. The maximum compression load considered corresponded to a biaxial loading ratio $\chi=-1.2$, which was two times the axial compressive load required to buckle the skin of the fuselage panel. 


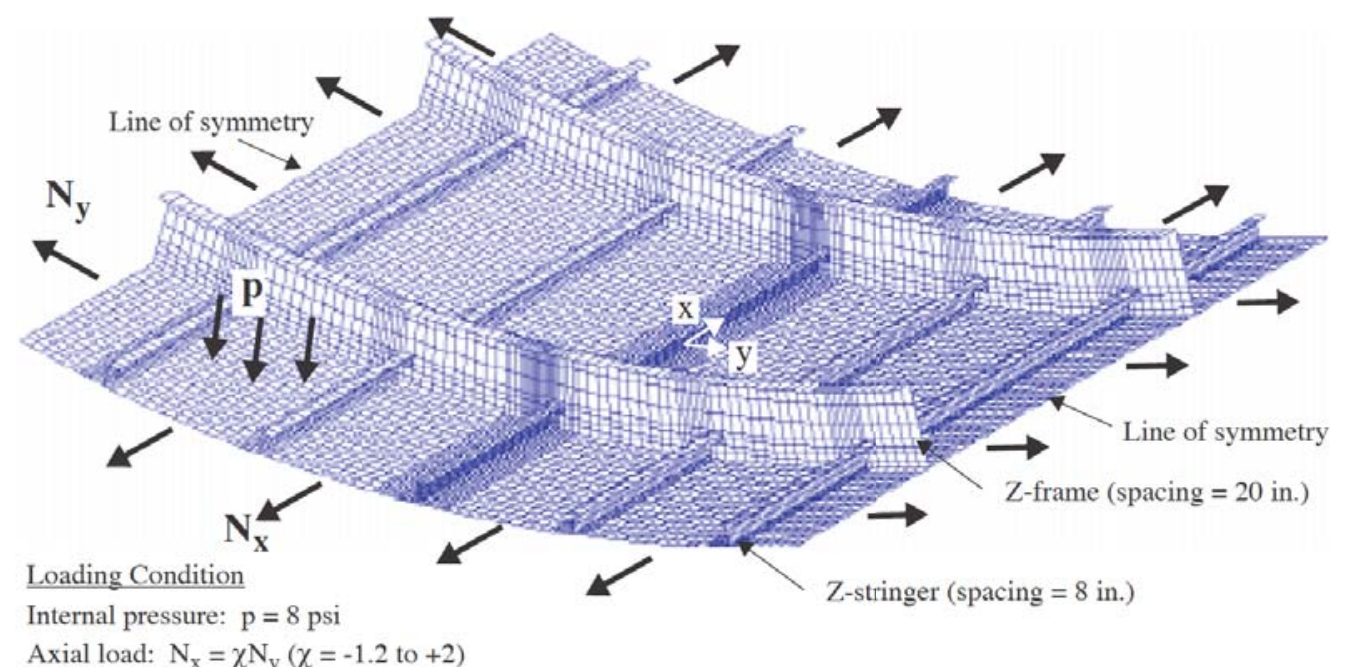

Axial load: $\mathrm{N}_{\mathrm{x}}=\chi \mathrm{N}_{\mathrm{y}}(\chi=-1.2$ to +2$)$
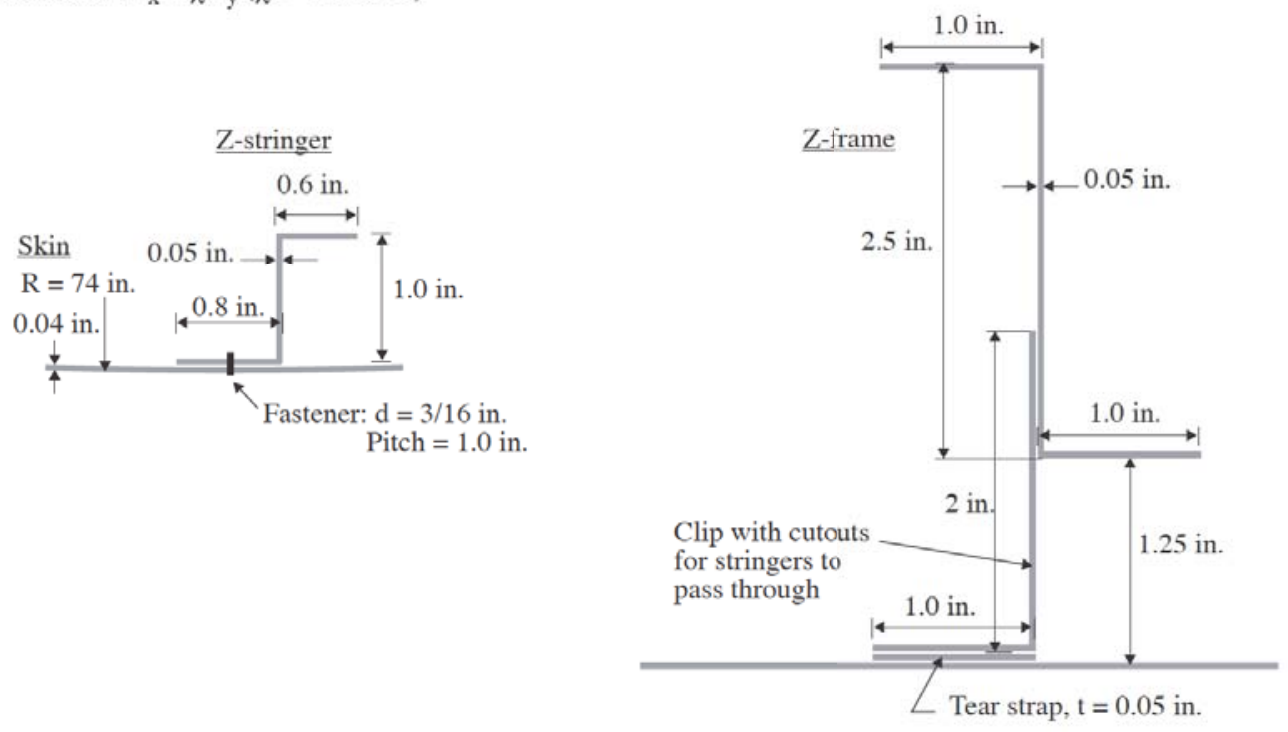

Figure 9. Geometry and finite element model of stiffened fuselage shell.

\section{Pristine Panel}

Nonlinear analyses were conducted for the fuselage panel with no damage. Solutions were obtained for an internal pressure load of $8 \mathrm{psi}$, and a range of axial loading values corresponding to biaxial loading ratio values $\chi=$ 2.0 to -1.2. Contour plots of the fuselage-skin radial displacement for $\chi=0.5$ and -1.0 are shown in Fig. 10. The case with $\chi=0.5$ corresponds to the bulkhead tension load for a nominal pressure load only. The radial displacement result for $\chi=0.5$, shown in Fig. 10a, shows that the internal pressure on the skin deforms the skin radially outward, and the displacements are smaller where the skin is attached to the stiffening structure. The circumferential stiffness of the frames strongly resists the radial deformation, thus the skin's radial displacement is the smallest near the frames. The stringers resist radial deformation because they are attached to the frames. The stringers provide some radial support to the skin through the bending stiffness of the stringers. The stringers bend along their length and deflect outward more than the frames, and the skin on each side of the stringer deflects outward more than the stringer. The skin radial displacement for $\chi=-1.0$, shown in Fig. 10b, displays a fullydeveloped buckled skin pattern that is symmetric with respect to each stringer and each frame. The symmetry in the response is attributed to the strong influence of the bending boundary layer on each side of the frames and the presence of the internal pressure load. Changes in the structural configuration would likely influence the 


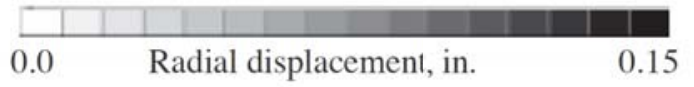

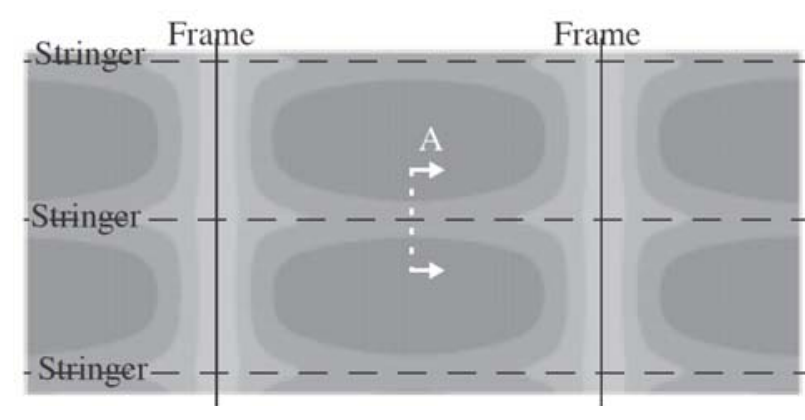

(a) $\chi=0.5$ (nominal pressure load)

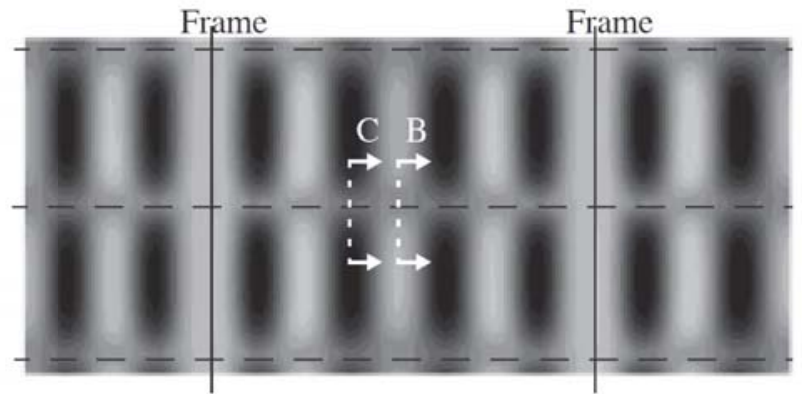

(b) $\chi=-1.0$

Figure 10. Fuselage-skin radial displacement for biaxial loading ratio values of $\chi=0.5$, and $\mathbf{- 1 . 0}$.

deformation shape and symmetry of the response. Panel cross-sections 'A', 'B' and 'C' are identified in Fig. 10. For each cross section, the deformed shape of the skin-stringer attachment area is shown amplified by a factor of 10 in Fig. 11. For the case with nominal pressure load, $\chi=0.5$, the deformed shape of cross section 'A', shown in Fig. $11 \mathrm{a}$, indicates a small amount of outward deformation in the skin on each side of the stringer, and a small amount of twisting in the stringer deformation due to the asymmetry of the stringer $\mathrm{Z}$ cross section. For the case with the postbuckled skin and $\chi=-1.0$, the deformed shape of cross section ' $\mathrm{B}$ ' shows the skin deformed toward the stringer and bent over the stringer, with contact evident in the skin-stringer interface. At cross section ' $\mathrm{C}$ ' of the postbuckled skin with $\chi=-1.0$, the deformed shape shown in Fig. 11c shows the skin pulled away from the stringer, which causes the asymmetric stringer to twist. The skin and stringer separate on one side of the fastener row (see Fig. 11c), and the bending response of the skin is most severe in this region. There are significant bending stresses associated with the skin bending shown in Figs. 11b and 11c. The large stress values located in the skin-stringer attachment region will increase the likelihood of damage initiation and propagation in this region.

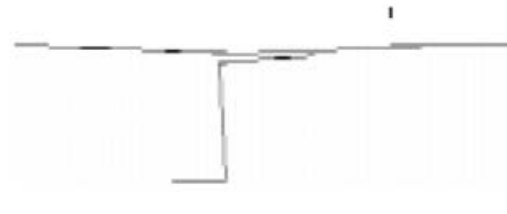

(a) $\chi=0.5$, non-buckled skin, cross-section 'A' in Fig. 10a

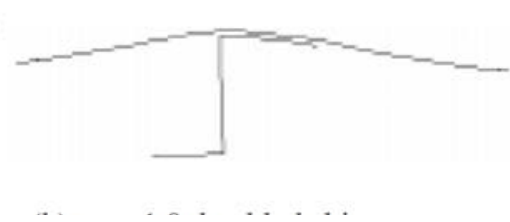

(b) $\chi=-1.0$, buckled skin, cross-section ' $B$ ' in Fig. 10b

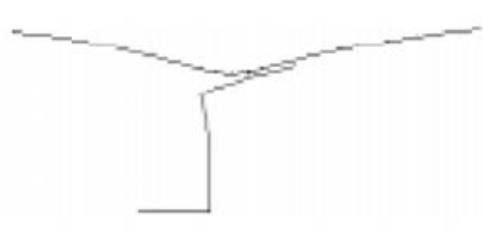

(c) $\chi=-1.0$, buckled skin, cross-section ' $\mathrm{C}$ ' in Fig. 10b

Figure 11. Deformed shape (10x) of the stringer cross-section for biaxial loading ration values of $\chi=0.5$, and $\mathbf{- 1 . 0}$.

\section{Centered 4-In.-Long Longitudinal Crack}

The effect of cracks on the response was studied by modifying the finite element model to include a 4-in.-long longitudinal crack in the panel skin. The crack was located midway between frames, centered on $x=0$ in Fig. 9, and adjacent to the line of skin-stringer attachment. Nonlinear analyses were conducted for an internal pressure load of $8 \mathrm{psi}$, and a range of axial load values corresponding to biaxial loading ratio values $\chi=2.0$ to -1.2 . Results obtained for all values of the biaxial loading ratio, indicate that the deformations associated with the 4-in.-long crack dominate the local panel response and skin buckling deformation. The internal pressure causes outward bulging of the skin near the crack, and these bulging deformations are magnified when the panel is subjected to compressive loads. The radial displacement is larger than in the pristine panel in the two skin bays adjacent to the crack, and the shape of the buckling deformation is different from the deformation in the remainder of the panel. Contour plots of the fuselage-skin radial displacement for biaxial loading ratio values $\chi=0.5$ and -1.0 are shown in Fig. 12 . The

13

American Institute of Aeronautics and Astronautics 
displacement results indicate that the presence of the 4-in.-long crack influences the radial displacement in one skin bay on each side of the center stringer. The influence is not confined to the skin bay on the side of the stringer where the crack is located, because the crack unloads the circumferential tension load in the skin, and the stringer is not stiff enough in the circumferential direction to prevent the adjacent skin bay from also unloading. The deformed shapes (3x magnification) of the center stringer near the 4-in.-long crack for biaxial loading ratio values of $\chi=0.5$ and -1.0 are shown in Fig. 13. The deformed shapes have significant displacements in the skin, but distortion of the stiffener cross-section appears to be minimal. The results of the analyses indicate that the stringer did not yield or collapse, and was able to support the additional loads developed by the crack.

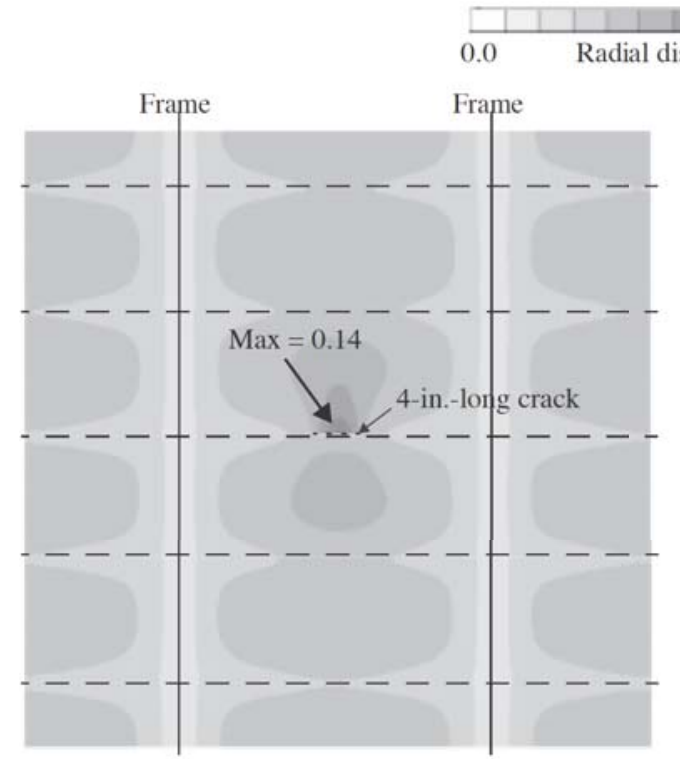

(a) $\chi=0.5$ (nominal pressure load)
0.25

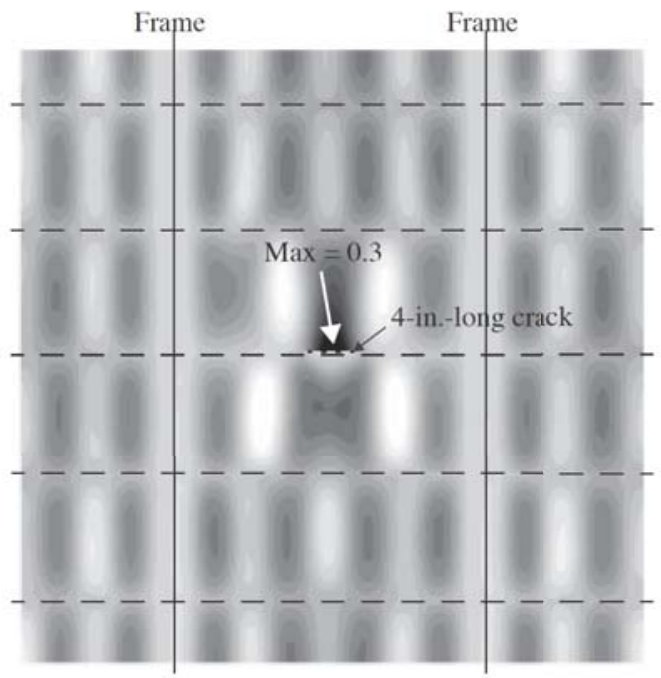

(b) $\chi=-1.0$

Figure 12. Radial displacement of fuselage-skin with a 4-inch-long longitudinal crack located midway between frames $(x=0.0)$ and adjacent to the center stringer, for biaxial loading ratio values of $\chi=0.5$ and 1.0.

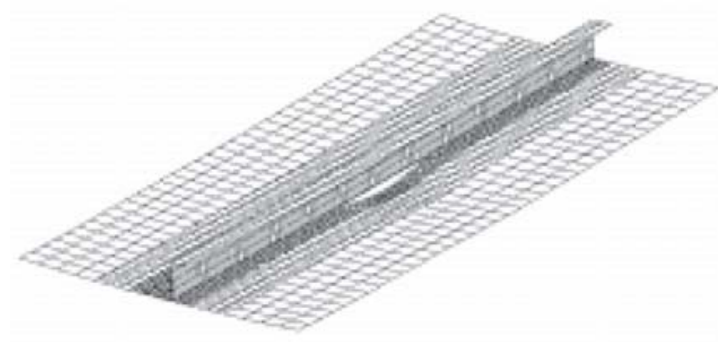

(a) $\chi=0.5$ (nominal pressure load)

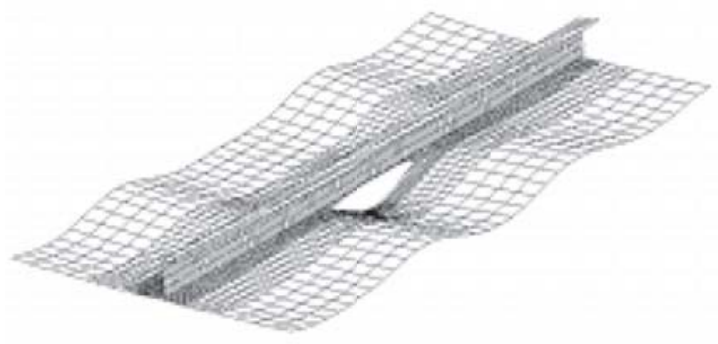

(b) $\chi=-1.0$

Figure 13. Deformed shape $(3 x)$ of the center stringer near a 4-inch-long crack for biaxial loading ratio values of $\chi=0.5$ and $\mathbf{- 1 . 0}$.

The effects of combined loads and buckling deformations on fastener forces were also assessed. The maximum forces in the fasteners that connect the skin to the center stringer are reported in Table 1 for biaxial loading ratio values $\chi=0.5$ and -1.0. The maximum fastener loads are considerably larger than the values for the pristine panel. Compared to the pressure-only case, $\chi=0.5$, cases with pressure plus axial tension, $\chi>0.5$, have smaller fastener 
forces. When axial compression is applied and the skin buckles, as is the case for $\chi=-1.0$, all of the fastener loads become significantly larger.

Table 1. Maximum fastener forces along the center stringer in a panel with a 4-in.-long longitudinal crack.

\begin{tabular}{ccccc}
\hline $\begin{array}{c}\text { Biaxial } \\
\text { loading } \\
\text { ratio, } \chi\end{array}$ & $\begin{array}{c}\text { Tension, } \\
\mathrm{lb} .\end{array}$ & $\begin{array}{c}\text { Axial } \\
\text { shear, } \\
\mathrm{lb}\end{array}$ & $\begin{array}{c}\text { Side } \\
\text { shear, } \\
\text { lb. }\end{array}$ & $\begin{array}{c}\text { Bending } \\
\text { moment, } \\
\text { in-lb. }\end{array}$ \\
\hline 0.5 & 18 & 58 & 55 & 3 \\
-1.0 & 81 & 328 & 115 & 8 \\
\hline \hline
\end{tabular}

Stress intensity factors for the 4-in.-long longitudinal crack are shown in Fig. 14 for biaxial loading ratio values of $\chi=2$ to -1.2 . In this figure, stress-intensity factors are normalized by the total stress intensity factor for the standard pressure-only condition. Results are shown for $K_{T}$, the symmetric and asymmetric membrane components, $K_{I}$ and $K_{I I}$, respectively, and the asymmetric bending component, $k_{2}$. For the pressure-only case, $\chi=0.5$, and cases with pressure plus axial tension, $\chi>0.5$, the crack-tip response is dominated by $K_{I}$, and the response is not very sensitive to variations in the biaxial loading ratio. When axial compression load is applied, $\chi<0.5$, the stress intensity factors increase in magnitude in a manner that is typical of a limit-load response, rather than a bifurcation buckling response. That is, the bulging deformation near the crack develops gradually with increasing compression load, rather than changing suddenly when the skin buckles. For the maximum compression load considered, $\chi=$ $-1.2, K_{I}$ is $70 \%$ larger than $K_{I}$ for the pressure-only case. Similarly, $k_{2}$ and $K_{I I}$ are $270 \%$ and $460 \%$ larger, respectively, for $\chi=-1.2$, than their respective values for a pressure load only, $\chi=0.5$. These elevated stress intensity factors can be related to accelerated crack growth rates and reduced residual strength. ${ }^{27}$

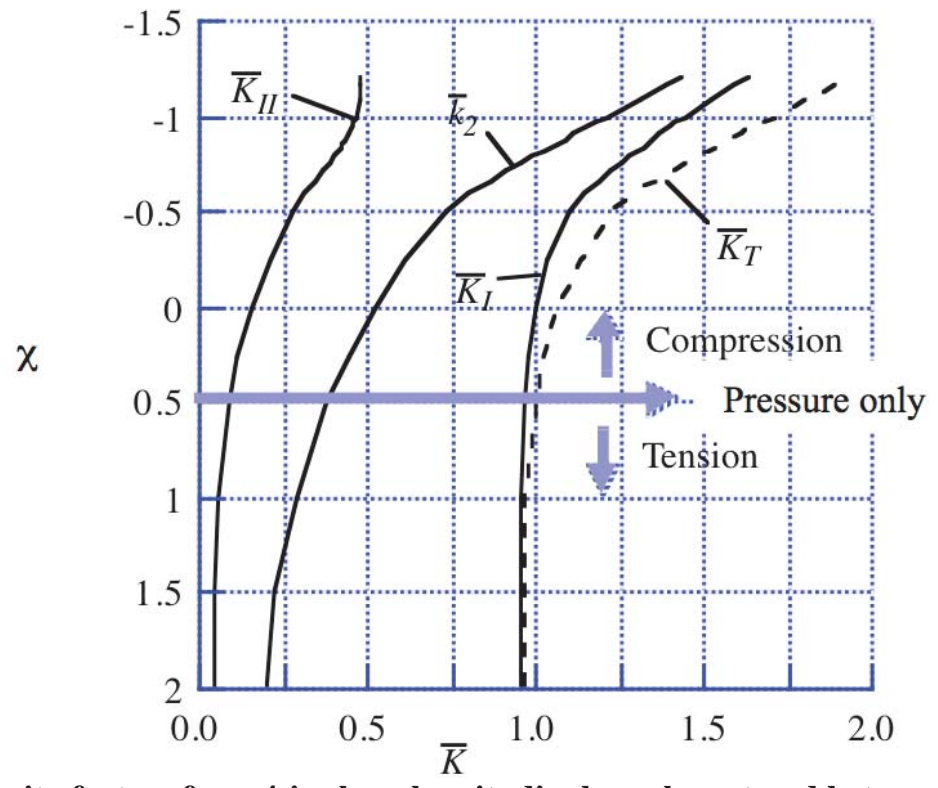

Figure 14. Stress intensity factors for a 4-in.-long longitudinal crack centered between frames and adjacent to the center stringer, for biaxial loading ratio values of $\chi=2$ to -1.2 ; normalized by $K^{T}=36 \mathrm{ksi} \sqrt{ } \mathrm{in}$. for $\chi=$ 0.5.

\section{Summary Remarks}

The results of this study indicate that nonlinear analyses of the stiffened-shell model can provide predictions of the geometric-nonlinear response of the buckled skin, cross section deformation of the stiffening components, and skin-stringer attachment forces associated with discrete fasteners. The numerical results indicate that compression loads and skin buckling can have a significant effect on the circumferential stress in the skin, and fastener loads, which will influence damage initiation. Compression loads and skin buckling have a comparable effect on stress 
intensity factors for cases with cracks, which will influence damage propagation rates and the residual strength of the panel.

\section{Advances in Residual Strength Analyses from Laboratory Coupons to Structural Components ${ }^{46}$}

This section describes the residual strength analysis methodology developed at NASA Langley Research Center for aluminum aircraft fuselage structures with cracks and subjected to combined internal pressure and mechanical loads. ${ }^{46}$ The methodology is applicable to complex built-up structure; accounts for combined loads, geometric nonlinearity, and material nonlinearity associated with elasto-plastic fracture; and is sufficiently general to include the effects of multiple-site damage on structural behavior.. The methodology is based on the critical crack-tipopening-angle $\left(\mathrm{CTOA}_{\mathrm{cr}}\right)$ fracture criterion that characterizes the fracture behavior of the structural material, and the STAGS $^{1}$ geometric and material nonlinear finite element shell analysis code that performs the structural analysis of the fuselage structure of interest. The methodology has been verified experimentally for structures ranging from laboratory coupons up to full-scale structural components. ${ }^{47-55}$ In the following sections, computational results based on this methodology are presented and compared with experimental data for aluminum-alloy laboratory-scale coupons and flat panels, small-scale pressurized shells, and full-scale curved stiffened panels.

\section{Compact Tension and Middle-Crack Tension Specimens}

Several studies have been conducted to confirm the use of the CTOA criterion in a STAGS two-dimensional analysis to predict the residual strength of a structure. In the first validation effort, geometrically nonlinear elasticplastic analyses were conducted to predict the response of compact-tension, $\mathrm{C}(\mathrm{T})$, and middle-crack tension, $\mathrm{M}(\mathrm{T})$, panels, with and without buckling constraints. For a particular material and thickness, the critical CTOA value was determined by conducting three-dimensional analyses, using ZIP3D, ${ }^{36,56}$ of $\mathrm{C}(\mathrm{T})$ and constrained $\mathrm{M}(\mathrm{T})$ tests to determine the $\mathrm{CTOA}_{\mathrm{cr}}$ that best correlated the experimental results. In the three-dimensional analysis the three dimensional constraint effects at the crack-tip are directly modeled, and the core height parameter, $h_{c}$ is eliminated. The angle determined from the three-dimensional analysis was then used in a two-dimensional simulation, performed using ZIP2D, ${ }^{57}$ of the constrained $\mathrm{M}(\mathrm{T})$ and $\mathrm{C}(\mathrm{T})$ tests, to determine the core height parameter that best correlated the experimental results. The fracture parameters determined in this manner were then used in a STAGS simulation of the response of the $\mathrm{C}(\mathrm{T})$ specimens and the constrained and unconstrained $\mathrm{M}(\mathrm{T})$ specimens.

Representative experimental and predicted crack extension results for 2024-T3 $C(T)$ and $M(T)$ panels are shown in Fig. 15 as a function of the applied load. These results verify the selection of CTOAcr and $h_{c}$ for this material and specimen thickness and indicate that the analyses with STAGS accurately predict the reduction in strength of the panels caused by the geometrically nonlinear effect of panel buckling.

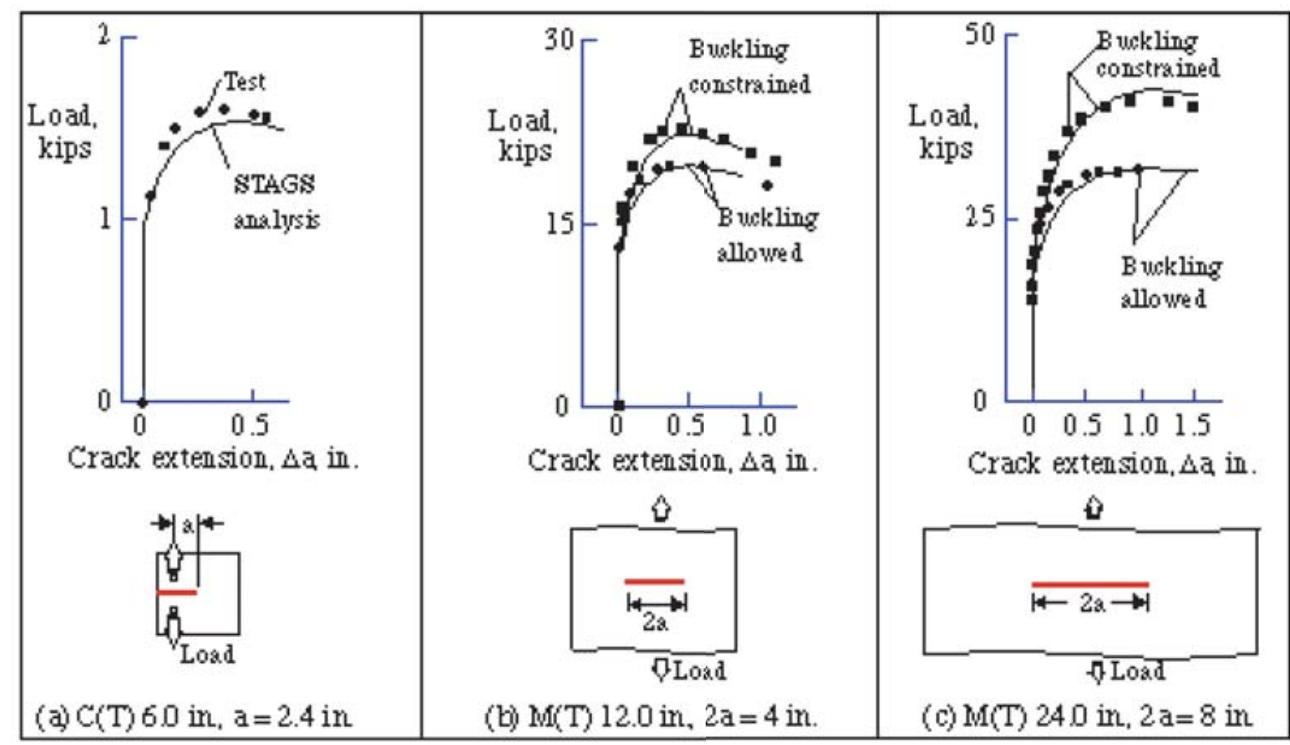

Figure 15. Load versus crack extension results from $C(T)$ and $M(T)$ tests, and nonlinear STAGS analyses with $\mathrm{CTOA}_{\mathrm{cr}}=5.0 \mathrm{deg}$. and $h_{\mathrm{c}}=0.04$ in. 


\section{Pressurized Cylindrical Shells}

An experimental and numerical study of the nonlinear response of thin unstiffened aluminum cylindrical shells with a longitudinal crack and subjected to internal pressure load was conducted. ${ }^{47}$ This study represents an effort to introduce in a simple configuration the effects of geometric and material nonlinearity on stable and unstable crack growth in aluminum structures. The primary objective of this study was to provide a preliminary validation of the crack-growth capability implemented in STAGS for curved, pressurized structure, and to validate the use of fracture parameters determined from standard fracture specimens for more complex structures and loading conditions.

Unstiffened cylindrical shells were fabricated from 0.04-inch-thick 2024-T3 aluminum-alloy sheets, with the rolling direction orientated circumferentially. The shells were 39-inches long, 18 inches in diameter, and had a 1.5inch wide double lap splice with 0.04-inch-thick splice plates and a single row of rivets on each side of the splice. The specimens were attached to end rings with an aluminum-filled epoxy potting material that extended 1.5 inches along the length from each end of the specimen. End plates with O-ring seals maintained internal pressure in the shell. A pressure line was attached to one end of the specimen and an instrumentation terminal block was attached to the other. One end ring of the specimens was clamped to rigid beams on the ground, and the other end was unconstrained in the axial direction to allow free expansion of the specimen. Each shell had a longitudinal crack that was simulated by a 0.01 -inch-wide saw cut at the specimen mid-length, diametrically opposite to the lapsplice. The crack tips were sharpened with a razor blade to simulate a fatigue crack and to insure some stable crack growth before the specimens failed. Specimens with initial crack lengths of 2, 3, and 4 inches were loaded by internal pressure until failure occurred. The crack length extension during pressurization was recorded using crack wire gages. ${ }^{47}$

Finite element analyses of the specimens were conducted assuming self-similar crack growth, and using the CTOA criterion as the condition for crack extension. The fracture parameters used in the simulations were determined by simulating the fracture behavior of compact tension, $\mathrm{C}(\mathrm{T})$ and middle-crack tension $\mathrm{M}(\mathrm{T})$ specimens, as described above, of the same material and thickness as the cylindrical shells. Internal pressure was simulated by applying a uniform lateral pressure to the shell wall and an axial tensile force to the ends of the shell. Multi-point constraints were used to enforce a uniform end displacement. The circumferential and radial degrees of freedom were constrained in the potted regions of the cylinder to approximate the experimental end conditions.

A typical result from the study is shown in Fig. 16 and demonstrated the ability of the analysis methodology to represent the experimentally observed response. Additionally, experimental and numerical results indicated that the pressure required to initiate stable crack growth and unstable crack growth in a shell subjected to internal pressure loads decreases as the initial crack length increases.

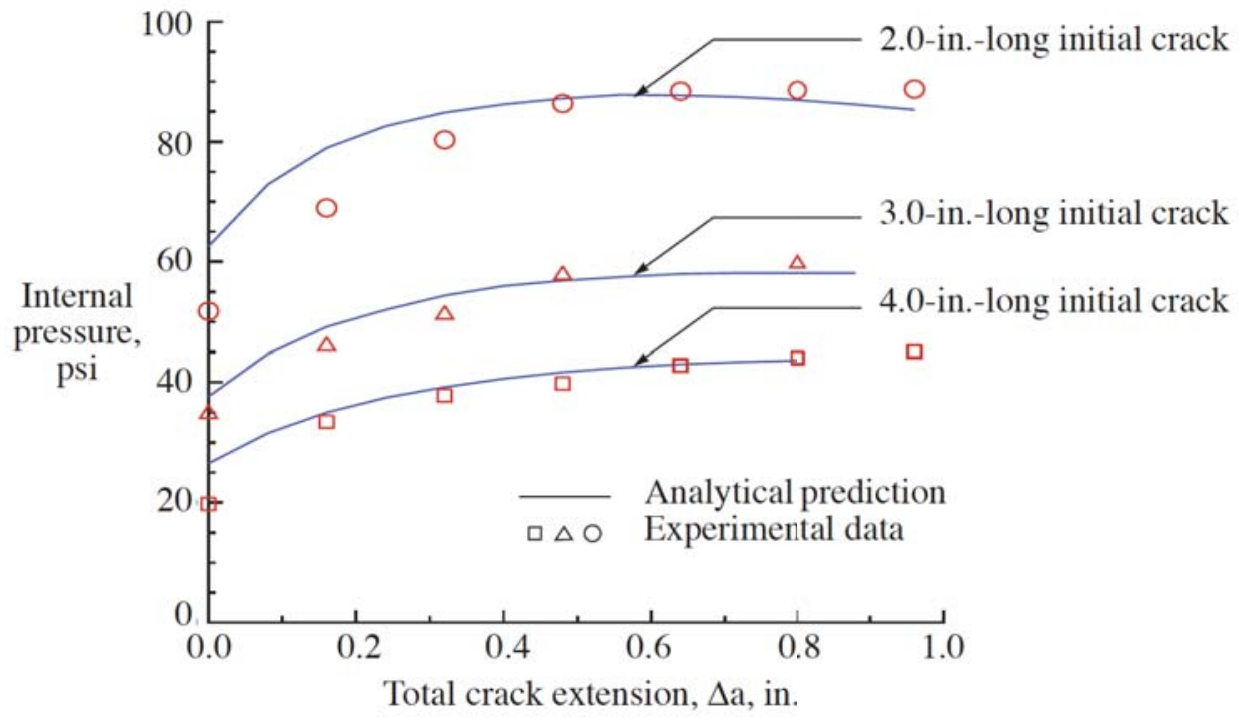

Figure 16. Comparison of numerical and experimental total crack extension results of 0.040 -inch-thick internally pressurized shells. 


\section{Flat Stiffened Panels}

Fracture tests were conducted on 40-inch-wide, 0.063-inch-thick, 2024-T3 aluminum alloy, flat, stiffened panel specimens. ${ }^{51}$ The stiffeners were made from 7075-T3 aluminum alloy and riveted to the specimens. The stiffeners were 1.6-inches wide and placed on both sides of the specimen, as illustrated in Fig. 17. The crack configuration consisted of a single 8-inch-long center crack with an array of twelve 3/16-inch-diameter holes on either side of the center crack. Specimens with and without multiple-site-damage (MSD) were tested. Specimens without MSD had the center crack and the holes only. Specimens with MSD cracking had 0.05-inch long cracks at the edges of each hole. The specimens were tested without guide plates to allow out-of-plane displacements.

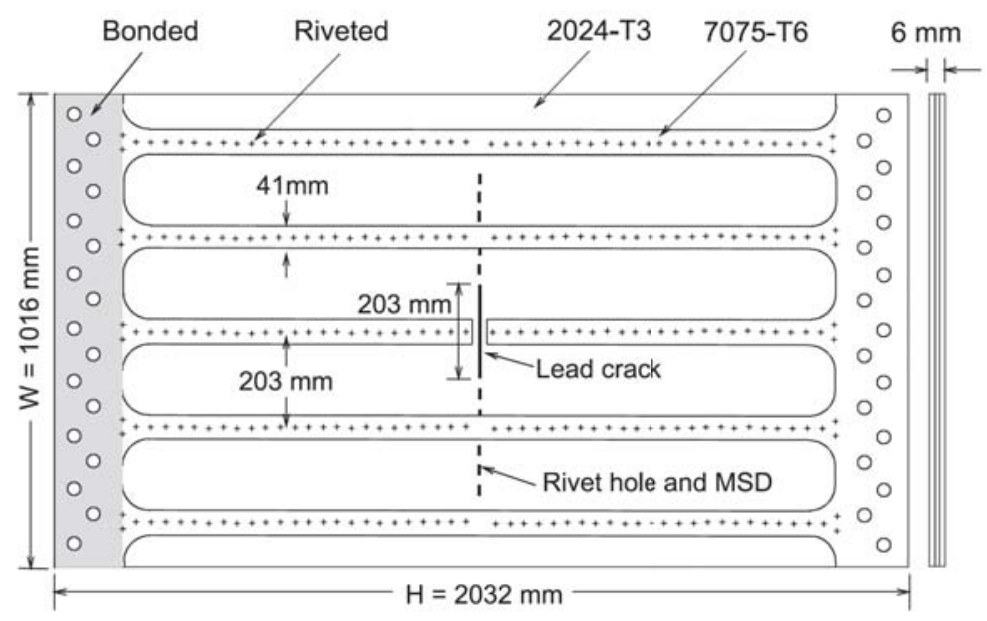

Figure 17. Wide stiffened flat panel and MSD configuration.

Predictions of the fracture behavior were conducted with the STAGS analysis code using a critical CTOA value obtained from smaller panel $\mathrm{C}(\mathrm{T})$ and $\mathrm{M}(\mathrm{T})$ tests. The configuration and loading condition were symmetric, so only a quarter of the sheet and stiffeners were modeled. The minimum element size along the line of crack extension was 0.04 inches. The analysis did not explicitly model the holes, but assumed that the holes with MSD cracks could be approximated with a crack with a length equal to the sum of the MSD crack lengths and the hole diameter. The rivet connections between the stiffener and sheet were modeled with nonlinear spring fastener elements with six degreesof-freedom. A bifurcation buckling analysis was conducted to determine the first buckling mode shape, and this shape was introduced as an initial geometric imperfection with an amplitude of $10 \%$ of the panel thickness for the nonlinear analysis. To prevent element interpenetration, contact elements and multi-point constraint conditions were used to allow the panel sheet and stiffener surfaces to contact or separate during the loading of the panel. Experimental measurements and finite element predictions for a stiffened panel with a single center crack are shown in Fig. 18. The results indicate that the analysis methodology represents the behavior of this specimen very well. Additional results in Ref. 51 indicate similar correlation was achieved for stiffened panels with MSD. The results from these tests and analyses confirmed a residual strength prediction capability for flat stiffened panels with MSD.

\section{Curved Stiffened Panels}

Three stringer- and frame-stiffened aluminum fuselage panels with longitudinal cracks were tested and analyzed at the NASA Langley Research Center to further validate the analysis methodology. ${ }^{52,53}$ These curved stiffened panels are referred to as Panels ASIP1, ASIP2, and ASIP3. Typical results are presented herein for Panels ASIP2 and ASIP3.

Panel ASIP2 has four stringers and three frames, and is shown prior to testing in Fig. 19a. ${ }^{52}$ The overall dimensions of this panel include a 122 -in. radius, a 72-in. length, and a 63-in. arc width. The skin is 0.063-in.-thick 2024-T3 aluminum alloy with the sheet rolling direction oriented parallel to the stringers. The stringers are 2024-T3 aluminum-alloy inverted hat-section stringers with a stringer spacing of 14 in. The frames are 2024-T3 aluminumalloy Z-section frames with a frame spacing of 22 in. There are 0.040-in.-thick 2024-T3 aluminum-alloy waffle tear straps, bonded to the skin, and located under the stringers and frames, but there are no tear straps midway between the frames. The stringers and frames are riveted to the skin and tear straps, and the frames are connected to the stringers by riveted stringer clips. Aluminum-alloy doublers are fastened to the curved ends of the panel between the stringers and along the sides of the panel between the frames to distribute the loads from the axial and 


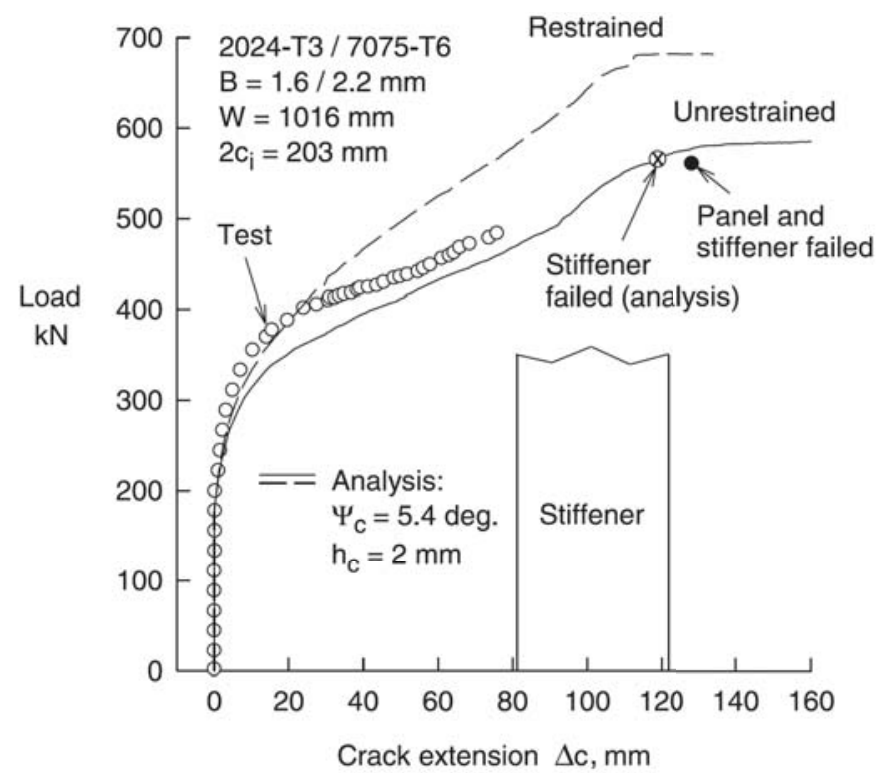

Figure 18. Experimental fracture measurements and STAGS finite element predictions for a 40-inch-wide 2024-T3 aluminum alloy stiffened panel with a single crack.

circumferential or hoop load introduction plates of the test fixture into the panel skin. There is a lap joint in this panel under the second stringer from the left as the panel is shown in Fig. 19a. In the lap joint, the skin from the right side of the panel is the outer skin and overlaps at a greater radius over the inner skin from the left side of the panel. The layers of the lap joint are connected with three rows of 0.125-in.-diameter countersunk fasteners. The fastener pitch in the longitudinal direction is $1.0 \mathrm{in}$., and the three rows of fasteners are spaced 1.33 in. in the circumferential direction with the middle row of fasteners centered on a hat-section stringer. The initial damage for panel ASIP2 consisted of a 10-in.-long longitudinal lead crack and MSD cracks along the edge of the lap joint. The 10-in.-long lead crack was located adjacent to the second stringer and centered on a severed frame, as indicated in Fig. 19a. A schematic of the lap joint, shown in Fig. 19b, indicates that the lead crack was along the third row of fasteners in the lap joint. The MSD cracks were introduced prior to panel assembly by making small longitudinal cuts in the outer skin of the lap joint that extend 0.05 in. on each side of the fastener countersink for each fastener in the third row of fasteners. The resulting initial damage state was a 10-in.-long longitudinal lead crack with 0.33-in.long MSD cracks in the outer skin, spaced ahead of the lead crack with a 1-in. pitch. The lead crack and MSD cracks were defined to be along the 'critical third row of fasteners' which is where lap joint eccentricity, pressure pillowing of the skin, and the fastener countersink combine to promote crack growth in the outer skin. The loading condition for panel ASIP2 was a combination of internal pressure plus axial tension loads. The axial load was prescribed to be equivalent to the bulkhead pressure load in a closed pressurized cylinder, and was applied during the test in proportion to the internal pressure load. Strain gages, linear variable displacement transducers, and video cameras were used to measure the panel response. Panel ASIP2 was tested in a pressure-box test machine. Details of the test fixture for panel ASIP2 are given in Ref. 52.

The test results for panel ASIP2 indicate that the panel failed as a result of MSD crack link up. Video record of the test did not show any visible crack growth for pressure levels less than 9.95 psig. When the pressure reached $9.95 \mathrm{psig}$, the lead crack suddenly extended on each end of the crack, and linked up with the series of MSD cracks ahead of the lead crack. The crack extended in the longitudinal direction in a fast fracture mode, and extended over the entire panel length in an instant. The crack growth behavior was symmetric with respect to the central severed frame. Photographs which characterize the failure of panel ASIP2 are shown in Fig. 20. A view of the outer surface of the panel is shown in Fig. 20a, which shows that the skin crack has extended the full length of the panel. A view of the inner surface of the panel is shown in Fig. 20b which shows that the skin crack has extended past the adjacent frame and tear strap, failing each of these components at fastener hole locations. A close-up of the crack trajectory is shown in Fig. 20c which shows the link-up of the MSD cracks along the row of fasteners with the lead crack growing to the right, and the MSD cracks growing to the left and right so that link-up occurs midway between the fasteners. 


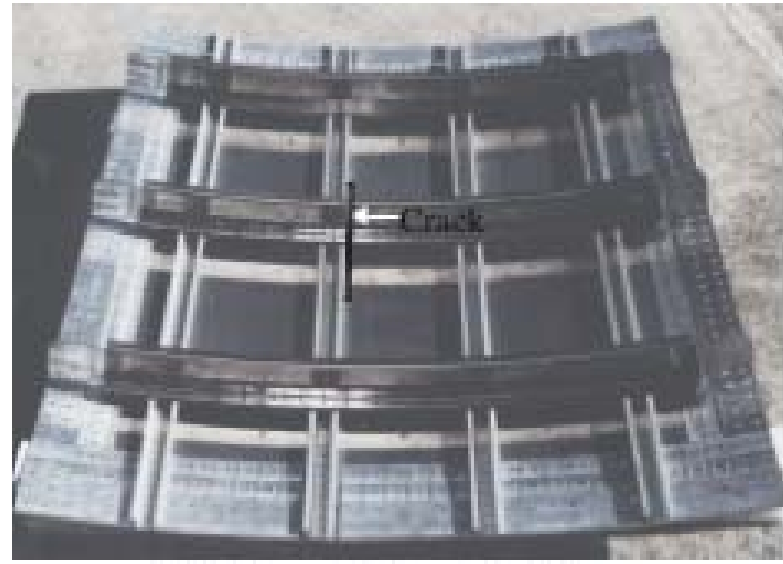

(a) Photograph of panel ASIP2

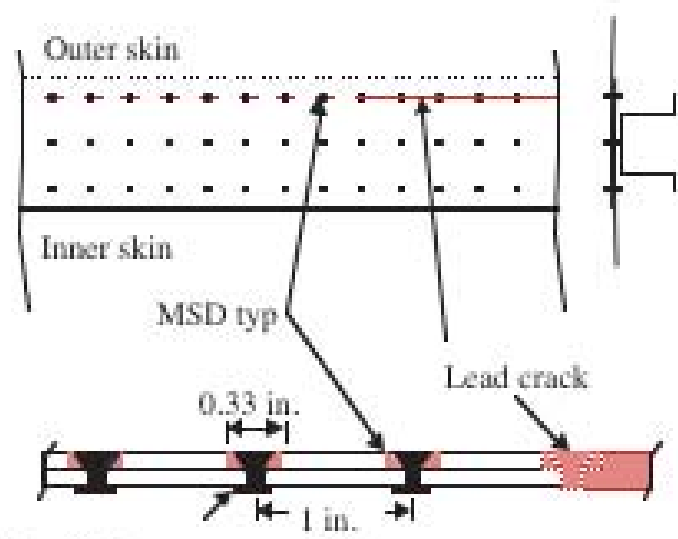

1/8-in. D fastener

(b) Lap joint detail with lead crack and MSD cracks

Figure 19. Fuselage panel ASIP2 with simulated multiple site damage along the third row of fasteners in a lap joint, shown prior to testing.

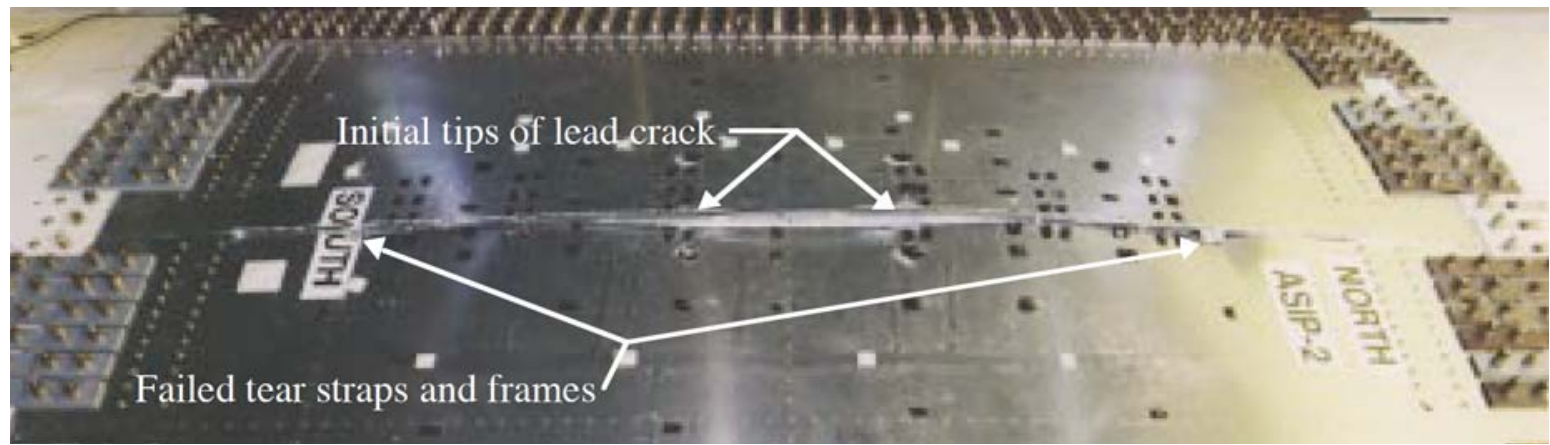

(a) Self-similar crack growth over the entire length of the panel, failing adjacent tear straps and frames

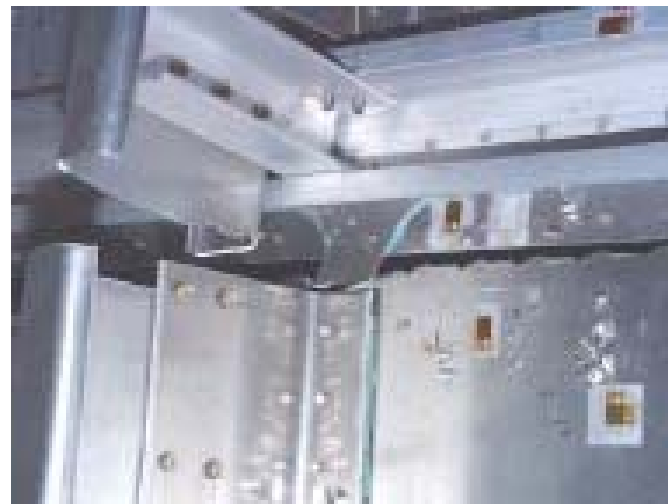

(b) Failed tear strap and frame

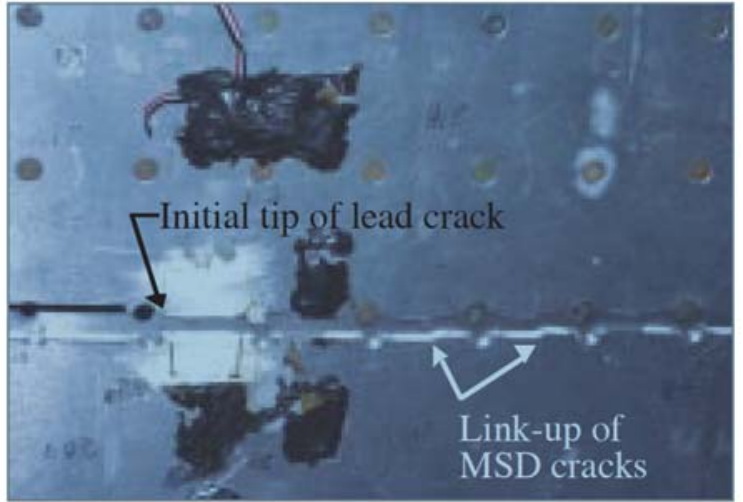

(c) Crack trajectory with link-up of MSD cracks

Figure 20. Panel ASIP2 after testing.

A typical analysis prediction with crack growth in the lead crack and the MSD cracks is shown in Fig. 21. The contour plot of the hoop stress in the region around the crack tip region, shown in Fig. 21a, indicates the high stress regions near the crack tips of the lead crack and the MSD cracks. A contour plot of the plastic strains in the hoop 


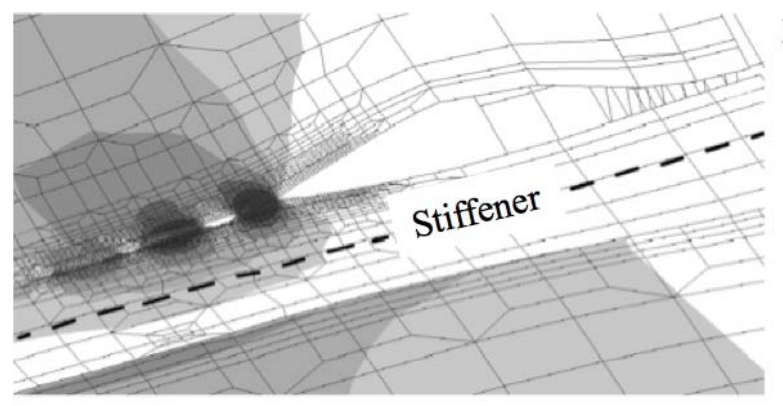

(a) Hoop stress, $\sigma_{y}$

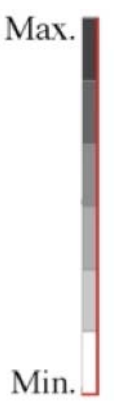

Min.

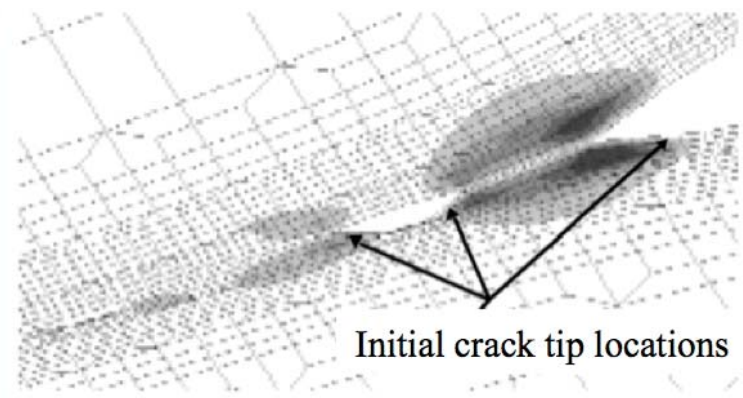

(b) Plastic hoop strain, $\left(\varepsilon_{y}\right)_{p}$

Figure 21. Typical analysis results for panel ASIP2 showing crack growth in the lead crack and MSD cracks.

direction is shown in Fig. 21b which indicates that there are regions of plastic deformation emanating from the lead crack and from the MSD crack tips, and that for the solution shown, the plastic zones from the lead crack and the first MSD crack have coalesced. The deformed shape shown in these plots indicates that the deformation on the side of the crack attached to the stiffener is much smaller than the deformation on the other side of the crack, demonstrating that the crack is not tearing due to a symmetric loading condition. The asymmetric loading could promote curvilinear crack growth, but it is assumed in the analysis that interaction between the lead crack and the MSD cracks will cause self-similar crack growth. The opening of the MSD cracks is also evident in the deformed shapes. The analysis predicted the residual strength of panel ASIP2 to within $11 \%$ of the experimentally observed value. For additional details on test and analysis correlation see Ref. 46.

Panel ASIP3 has 12 stringers and five frames, and is shown prior to testing in Fig. 20. The overall dimensions of the panel include a 122-in. radius, a 120-in. length, and a 120-in. arc width. The initial damage for panel ASIP3 was a 10-in.-long longitudinal crack, located midway between stringers and centered on a severed frame, as indicated in Fig. 22. Panel ASIP3 was tested in the COLTS combined loads test machine indicated in Fig. 22. The panel was attached to the D-box test fixture shown in the figure, and the panel was subjected to internal pressure, axial compression and torsion loads. The loading sequence for the panel consisted of applying the internal pressure load, followed by the axial compression load, and then followed by the torsion load. Details of panel ASIP3 and the test fixture are given in Ref. 53.

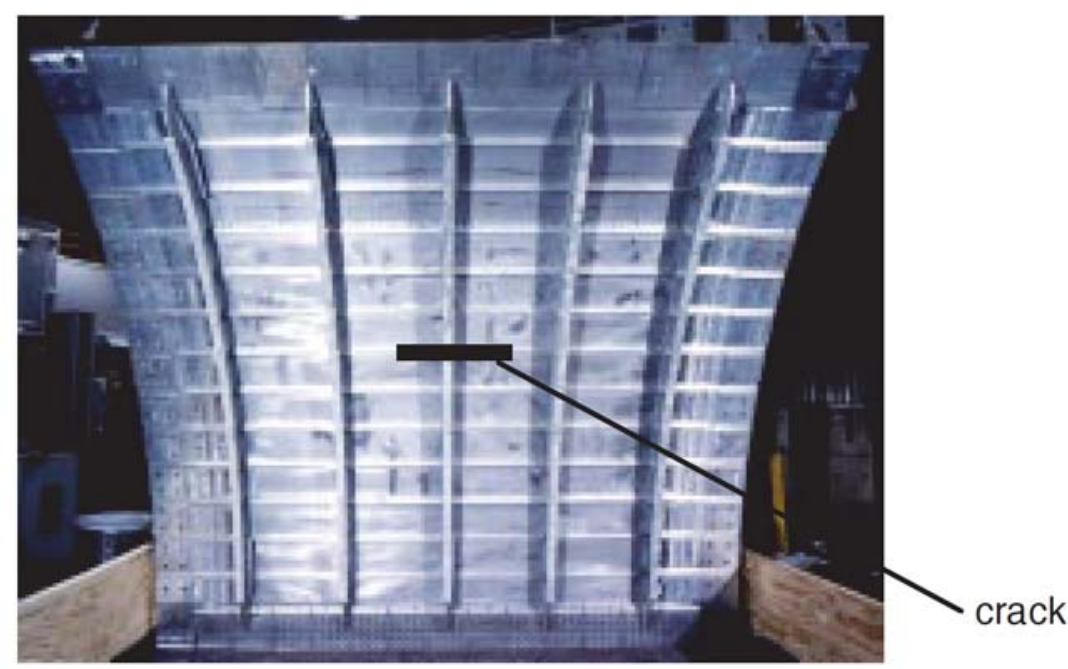

Figure 22. Panel ASIP3 prior to testing. 


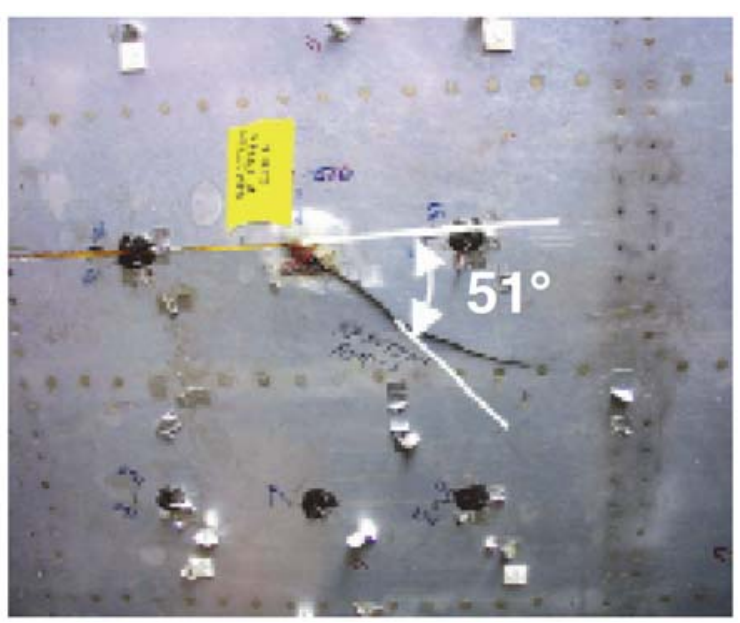

(a) Experimental results

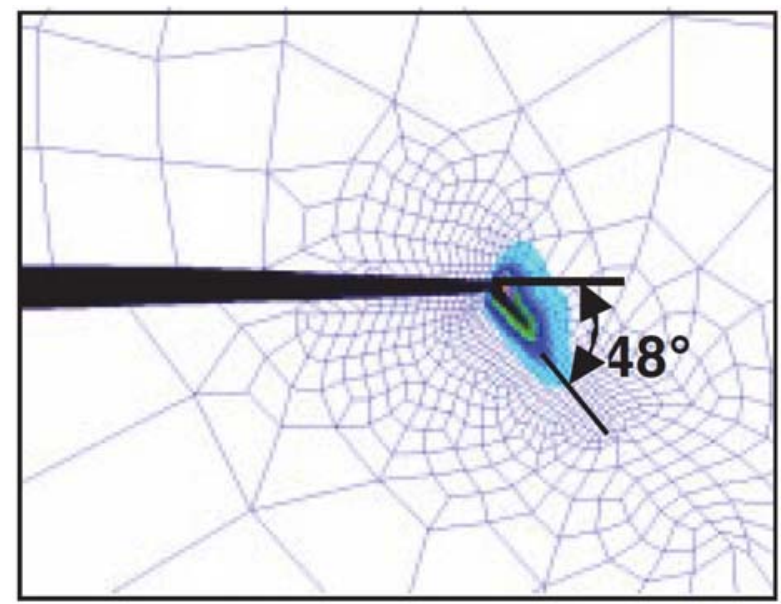

(b) Analysis prediction

Figure 23. Experimentally observed and predicted crack-growth trajectory for Panel ASIP3.

The test results for panel ASIP3 indicate that the panel failed as a result of non-self-similar crack propagation. No crack growth was observed when the internal pressure and axial compression loads were applied. The torsion load was increased in magnitude until the crack propagated. A comparison of the numerically predicted crack growth trajectory and the test results for panel ASIP3 is shown in Fig. 23 indicating that the CTOA criterion and the nonlinear STAGS analysis predicted the crack growth trajectory very well for this combined loading condition. Details of the test and analysis results for panel ASIP3 are given in Ref. 53.

\section{Summary Remarks}

The results presented in this section demonstrate the fidelity of the residual strength analysis methodology developed at NASA Langley Research Center for aluminum aircraft fuselage structures with cracks and subjected to combined internal pressure and mechanical loads. The methodology is based on the critical crack-tip-opening-angle fracture criterion that characterizes the fracture behavior of a material of interest, and a geometric and material nonlinear finite element shell analysis code that performs the structural analysis of a fuselage structure of interest. The results indicate that elastic-plastic effects in a thin sheet can be effectively represented by a critical-crack-tipopening angle fracture criterion. The results also indicate that geometric and material nonlinear structural analyses can accurately represent the changes in internal load distributions, local stress and displacement gradients, and crack growth behavior in stiffened fuselage shells that are subjected to combined internal pressure and mechanical loads and have long cracks.

\section{Curvilinear Crack Growth}

For situations were the crack growth is not self-similar and the crack path is not known a-priori, crack turning criteria and nonlinear adaptive mesh capabilities are required to determine when a crack will turn, the direction of crack growth, and the necessary finite element model changes as the crack propagates. A unique capability was developed that integrated the fracture topology modeling capabilities of FRANC $3 \mathrm{D}^{3,4}$ with the general shell analysis capabilities of STAGS into an integrated FRANC3D - STAGS analysis procedure. The developed procedure was used to study the effects of loading conditions and initial crack location and orientation on crack growth characteristics in fuselage shells subjected to combined internal pressure and mechanical loads. Typical analysis models and results from a study are shown in Figs. 24 and 25 for a fuselage shell subjected to internal pressure and shear and bending. A global-local modeling scheme, shown in Fig. 24, was used to simulate stable tearing for a 6in.- (15.24-cm-) long skin crack centered over a broken tear strap. First, a STAGS finite element analysis of a full fuselage barrel section was conducted to compute edge displacements for a six-bay by six-bay model. A FRANC3D fracture analysis was then performed using a local two-bay by two-bay geometry model, with the edge displacements determined from the six-bay by six-bay model. The stress contour plot in the upper right of Fig. 25 shows the hoop stress resultants for the initial crack length of $6.0 \mathrm{in} .(15.24 \mathrm{~cm})$, obtained using the finite element mesh shown in Fig. 24. The FRANC3D adaptive remeshing capability was used to extend the crack to 8.0 in. (20.32 $\mathrm{cm})$ and then to 10.0 in. $(25.4 \mathrm{~cm})$, as shown in the two lower stress contour plots in Fig. 25. The direction of crack 
extension was determined using a maximum principal stress criterion. The FRANC3D adaptive remeshing algorithms automatically developed new finite element meshes for the 8-and 10-in. crack geometries. The lack of symmetry in the loading and geometry results in a nonsymmetric and non-self-similar crack extension.
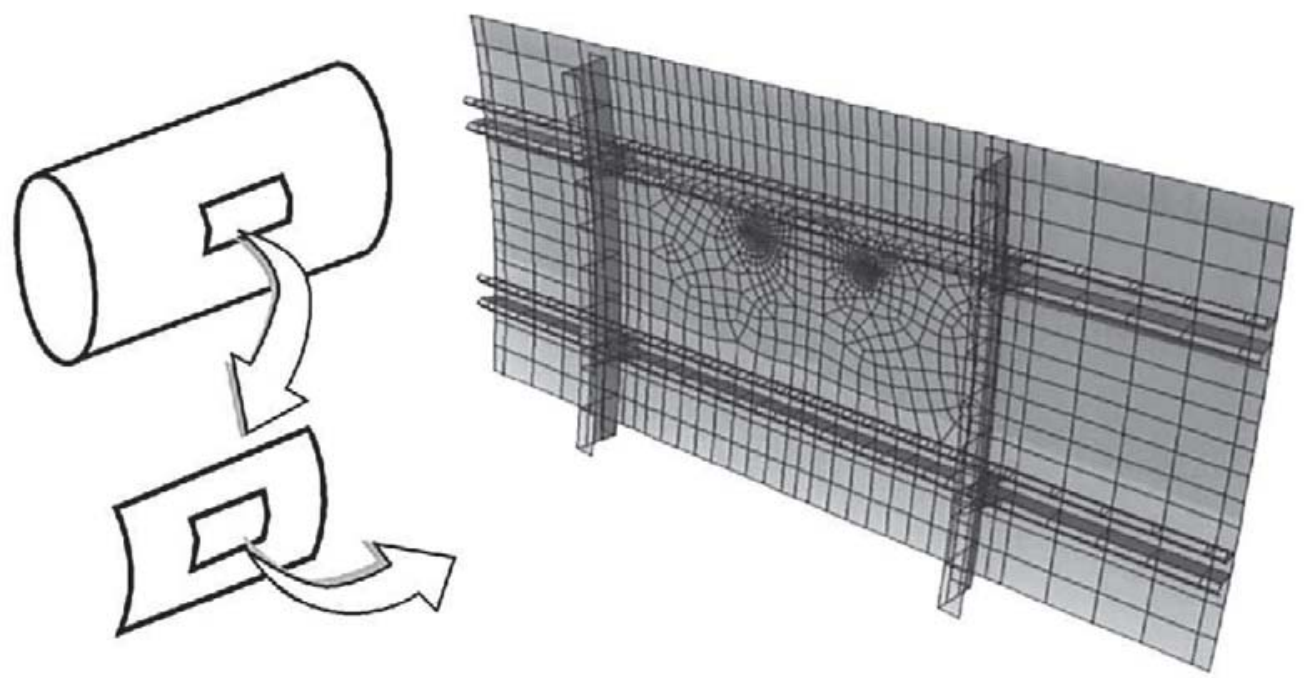

Figure 24. Curvilinear crack growth prediction using FRANC3D-STAGS.

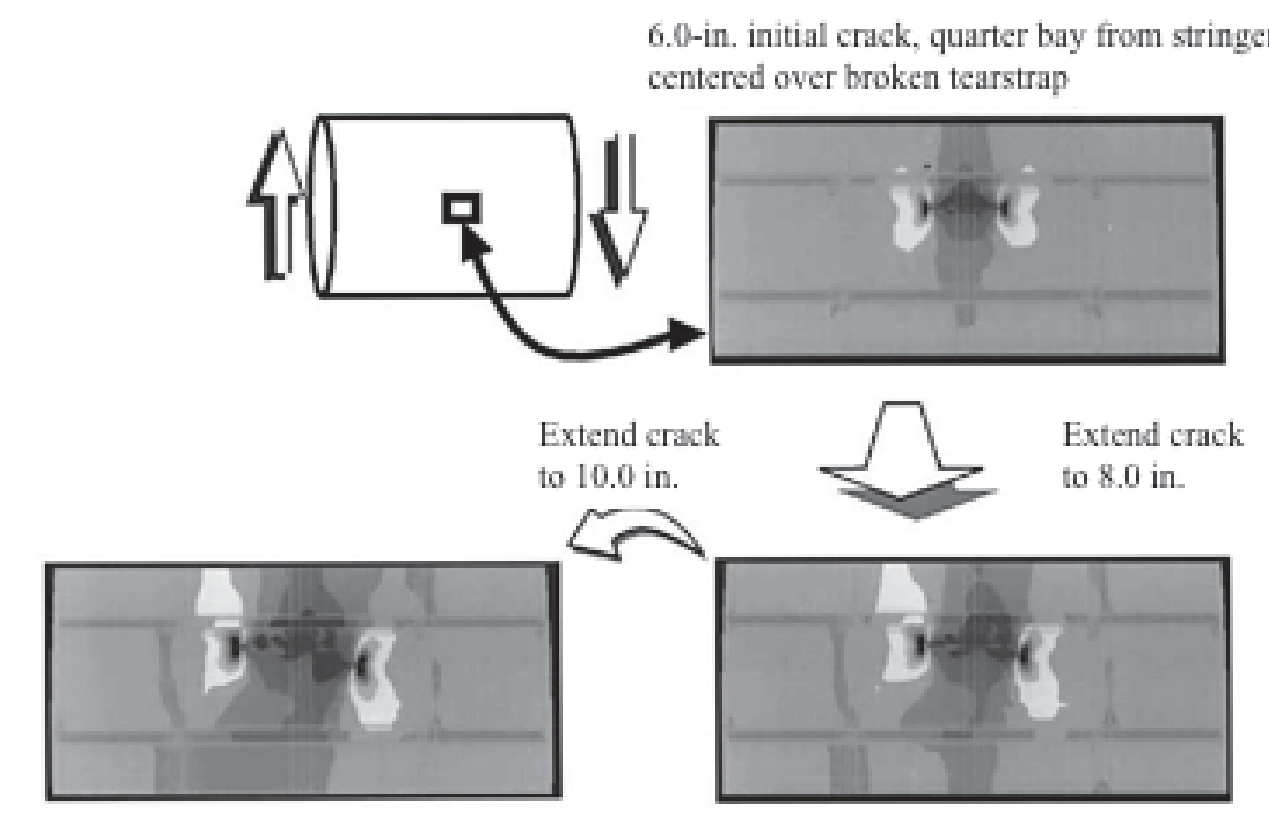

Figure 25. Curvilinear crack extension: internal pressure plus shear loading.

\section{Concluding Remarks}

Concern for the safety of an aging commercial aircraft fleet led to national initiatives to develop the capability to predict the residual strength of metallic fuselage structures with long cracks or multiple site damage. A summary of advances in the Structural Analysis of General Shells (STAGS) finite element code that were realized under the NASA Airframe Structural Integrity Program (NASIP) through collaboration between the structures 
group at NASA Langley, and Dr. Charles Rankin was presented. These advances included crack modeling capability including stress intensity factors computed from strain energy release, elastic-plastic fracture analysis based upon a critical crack-tip-opening-angle $\left(\mathrm{CTOA}_{\mathrm{cr}}\right)$ criterion, implementation of a plane-strain core to simulate 3D constraint near a crack tip, and coupling with the FRANC3D code to model non-self-similar crack extension. Studies using the STAGS code that were conducted to develop improved understanding of the nonlinear response of cracked fuselage structures subjected to combined loads were presented. Studies on crack bulging demonstrated non-linear effects of shell curvature and biaxial loading on crack intensity factors that led to improvements in design methodology for damage tolerance of curved shells. Experimental and analytical studies of stiffened shells demonstrated the effect of stiffening structure and combined pressure and mechanical loads on crack growth. Finally, results were presented to demonstrate the integrated residual strength analysis methodology for metallic structure that was developed during the NASIP using the STAGS code to model a growing crack and the effect of crack growth on structural integrity. The analysis capability and the understanding obtained from related analytical and experimental studies collectively represent significant achievement toward being able to evaluate the structural integrity of fuselage structure with cracks and ensure the continued safe operation of aging aircraft.

\section{References}

1 Swift, T., "Damage Tolerance in Pressurized Fuselages," New Materials and Fatigue Resistant Aircraft Design, D. L. Simpson, Ed., EMAS Ltd., 1987, pp.1-77.

2 Rankin, C. C., Brogan, F. A., Loden, W. A. and Cabiness, H. D., "STAGS User Manual, Version, 5.0," Lockheed Martin Missiles \& Space Co., Inc., Rept. LMSC P032594, January 2005.

3 Wawrzynek, P. A., and Ingraffea, A. R., “FRANC2D: A Two-Dimensional Crack Propagation Simulator Version 2.7 User's Guide,'’ NASA CR 4572, March 1994.

4 Potyondy, D. O., Wawrzynek, P. A., and Ingraffea, A. R., "'Discrete Crack Growth Analysis Methodology for Through Cracks in Pressurized Fuselage Structures," Proceedings of the FAA/NASA International Symposium on Advanced Structural Integrity Methods for Airframe Durability and Damage Tolerance, edited by C. E. Harris, NASA Langley Research Center, Hampton, VA, 1994, pp. 581 - 602.

5 Rankin, C. C., Riks, E. Brogan, F., "Residual Strength Calculations of Stiffened Metal Panels Containing Cracks," AIAA Paper No. 2005-2007, April 2005.

6 Riks, E., den Reijer, P. J., "A Finite Element Analysis of Cracks in a Thin Walled Cylinder under Internal Pressure," NLR TR87021 U, National Aerospace Laboratory, the Netherlands, 1987.

7 Riks, E., "Bulging Cracks in Pressurized Fuselages: A Numerical Study," NLR Report NLR-MP-87058 U, NLR National Aerospace Laboratory, The Netherlands, 1987.

8 Riks, E., Brogan, F. A., and Rankin, C. C., "Bulging Cracks in Pressurized Fuselages: A Procedure for Computation," in Analytical and Computational Models of Shells, Noor, A. K., Belytschko, T., and Simo, J. C., eds., The American Society of Mechanical Engineers, ASME-CED, Vol. 3, 1989.

9 Folias, E. S., "An Axial Crack in a Pressurized Cylindrical Shell," International Journal of Fracture Mechanics, Vol. 1, No. 2, 1965, pp. 104-113.

${ }^{10}$ Folias, E. S., "A Circumferential Crack in a Pressurized Cylindrical Shell," International Journal of Fracture Mechanics, Vol. 3, 1967, pp. 1-12.

${ }^{11}$ Folias, E. S., "On the Effect of Initial Curvature on Cracked Flat Sheets," International Journal of Fracture Mechanics, Vol. 5, No. 4, December 1969, pp. 327-346.

12 Folias, E. S., "Asymptotic Approximations to Crack Problems in Shells," Mechanics of Fracture - Plates and Shells with Cracks, G. C. Sih, H. C. van Elst, and D. Broek, eds., Noordhoff International, Leyden, 1977, pp. 117-160.

13 Copely, L. G., and Sanders, J. L., Jr., "A Longitudinal Crack in a Cylindrical Shell under Internal Pressure," International Journal of Fracture Mechanics, Vol. 5, No. 2, June 1969, pp. 117-131.

${ }^{14}$ Erdogan, F., and Kibler, J. J., "Cylindrical and Spherical Shells with Cracks," International Journal of Fracture Mechanics, Vol. 5, No. 3, September 1969, pp. 229-237.

15 Erdogan, F., and Ratwani, M., "Fatigue and Fracture of Cylindrical Shells Containing a Circumferential Crack," International Journal of Fracture Mechanics, Vol. 6, No. 4, September 1970, pp. 379-392.

16 Duncan-Fama, M. E., and Sanders, J. L., Jr., "A Circumferential Crack in a Cylindrical Shell under Tension," International Journal of Fracture Mechanics, Vol. 8, No. 1, March 1972, pp. 15-20.

17 Peters, Roger W., and Kuhn, Paul, "Bursting Strength of Unstiffened Pressure Cylinders with Slits," NACA TN 3993, April 1957.

18 Anderson, Robert B., and Sullivan, Timothy L., "Fracture Mechanics of Through-Cracked Cylindrical Pressure Vessels," NASA TN D-3252, February 1966.

19 Chen, D., "Bulging of Fatigue Cracks in a Pressurized Aircraft Fuselage," Ph.D. Thesis, Delft University of Technology, Delft, The Netherlands, Report LR-647, October 1990. 
${ }^{20}$ Jeong, D. Y., and Tong, P., "Nonlinear Bulging Factor Based on R-Curve Data," Proceedings of the FAA/NASA International Symposium on Advanced Structural Integrity Methods for Airframe Durability and Damage Tolerance, September 1994, pp. 327-338.

21 Bakuckas, J. G., Ngugen, P. V., and Bigelow, C. A., "Engineering Fracture Parameters for Bulging Cracks in Pressurized Unstiffened Curved Panels," Proceedings of the FAA-NASA Symposium on Continued Airworthiness of Aircraft Structures, DOD/FAA/AR-97/2, 1996.

${ }^{22}$ Bakuckas, J. G., Jr., Nguyen, P. V., Bigelow, C. A., and Broek, D., "Bulging Factors for Predicting Residual Strength of Fuselage Panels," Presented at the International Conference on Aeronautical Fatigue, Edinburgh, Scotland, June 1820, 1997.

${ }^{23}$ Starnes, J. H., Jr., Britt, Vicki O., and Rankin, C. C., "Nonlinear Response of Damaged Stiffened Shells Subjected to Combined Internal Pressure and Mechanical Loads," AIAA Paper 95-1462, April 1995.

24 Starnes, J. H., Jr., Britt, V. O., Rose, C. A., and Rankin, C. C., "Nonlinear Response and Residual strength of Damaged Stiffened Panels Subjected to Combined Loads," AIAA Paper No. 96-1555, April 1996.

25 Starnes, J. H., Jr., Rose, C. A., Young, R. D., and Rankin, C. C., "Effects of Combined Loads on the Nonlinear Response of Stiffened Shells with Long Cracks," Presented at the 19th International Committee on Aeronautical Fatigue Symposium, Edinburgh, Scotland, UK, June 18-20, 1997.

${ }^{26}$ Riks, E., "Some Computational Aspects of the Stability Analysis of Nonlinear Structures," Computational Methods in Applied Mechanics and Engineering, Vol. 47, 1984, pp. 219-259.

27 Riks, E., "Progress in Collapse Analysis," Journal of Pressure Vessel Technology, Vol. 109, 1987, pp. 27-41

28 Rankin C. C., Brogan F. A. (1984), An Element Independent Corotational Procedure for the Treatment of Large Rotations, Collapse Analysis of Structures, edited by L. H. Sobel and K. Thomas, ASME, New York, 1984.

${ }^{29}$ Rankin, C. C., Noor, O. B., "The Use of Projectors to Improve Finite Element Performance," Computers and Structures, Vol. 10, No. 1/2, 1988, pp. 257-267.

30 Besseling, J. F., and van der Giessen, E., "Mathematical Modeling of Inelastic Deformation," Chapman \& Hall, 2-6 Boundary Row, London, SEI 8HN, UK, 1994.

31 Rankin, C. C., Brogan, F. A., and Riks, E., "Some Computational Tools for the Analysis of Through Cracks in Stiffened Fuselage Shells," Computational Mechanics, Springer International, Vol. 13, No. 3, December 1993, pp. 143156.

32 Newman, J. C., Jr., "Finite Element Analyses of Fatigue Crack Propagation -- Including the Effects of Crack Closure," Ph.D. Thesis, Virginia Polytechnic institute and State University, Blacksburg, VA, May 1974.

${ }^{33}$ Newman, J., C., Jr., "An Elastic-Plastic Finite Element Analysis of Crack Initiation, Stable Crack Growth and Instability," ASTM STP 833, 1984, pp. 93-117.

34 Dawicke, D. S., Sutton, M. A., Newman, J. C., Jr., and Bigelow, C. A., "Measurement and Analysis of Critical CTOA for Thin-Sheet Aluminum Alloy Materials, In: Erdogan, F., editor, Fracture Mechanics: $25^{\text {th }}$ Volume, ASTM STP 1220, 1995, pp. 358-79.

35 Dawicke, D. S., Newman, J.C., Jr., and Bigelow, C. A., "Three-Dimensional CTOA and Constraint Effects During Stable Tearing in a Thin-Sheet Material," In Fracture Mechanics: 26th Volume, ASTM STP 1256, 1995, pp. $223-242$.

${ }^{36}$ Newman, J. C., Jr., Booth, B. C., Shivakumar, K. N., "An Elastic-Plastic Finite-Element Analysis of the J-Resistance Curve Using a CTOD Criterion," In: Read, D. T., Reed, R. P., editors, Fracture Mechanics: $18^{\text {th }}$ Volume, ASTM STP 945, 1988, pp. 665-85.

37 Abaqus Theory Manual, Version 5.5, Hibbit, Karlsson, Sorensson, 1995.

38 Rybicki, E. F., and Kanninen, M. F., “A Finite Element Calculation of Stress Intensity Factors by a Modified Crack Closure Integral,” Engineering Fracture Mechanics, Vol. 9, 1977, pp. 931-938.

39 Hui, C. Y., and Zehnder, A. T., "A Theory for the Fracture of Thin Plates Subjected to Bending and Twisting Moments," International Journal of Fracture, Vol. 61, No. 3, 1993, pp. 211-229.

40 Young, R. D., Rose, C. A., and Starnes, J. H., Jr., "Nonlinear Bulging Factors for Longitudinal and Circumferential Cracks in Cylindrical Shells Subjected to Combined Loads," Proceedings of the 41st AIAA/ASME/ASCE/AHS/ASC Structures, Structural Dynamics and Materials Conference, Atlanta, GA, April 2000, AIAA Paper No. 2000-1514.

${ }^{41}$ Young, R. D., Rose, C. A., and Starnes, J. H., Jr., "Nonlinear Local Bending Response and Bulging Factors for Longitudinal and Circumferential Cracks in Pressurized Shells," Proceedings of the 3rd Joint FAA/DoD/NASA Conference on Aging Aircraft, Albuquerque, NM, September 20-23, 1999.

42 Rose, C. A., Young, R. D., and Starnes, J. H., Jr., "Nonlinear Local Bending Response and Bulging Factors for Longitudinal Cracks in Pressurized Cylindrical Shells," Proceedings of the 40th AIAA/ASME/ASCE/AHS/ASC Structures, Structural Dynamics, and Materials Conference, St. Louis, MO, April 12-15, 1999, AIAA Paper No. 991412 .

43 Budiman, H. T., and Lagace, P. A., "Nondimensional Parameters for Geometric Nonlinear Effects in Pressurized Cylinders with Axial Cracks," Journal of Applied Mechanics, Vol. 64, 1997, pp. 401-407.

${ }^{44}$ Budiman, H. T., "Mechanisms of Damage Tolerance and Arrest in Pressurized Composite Cylinders," Ph.D. Thesis, Department of Aeronautics and Astronautics, Massachusetts Institute of Technology, Cambridge, MA, 1996.

45 Young, R. D., Rose, C. A., and Starnes, J. H., Jr., "Skin, Stringer, and Fastener Loads in Buckled Fuselage Panels," Proceedings of the 42st AIAA/ASME/ASCE/AHS/ASC Structures, Structural Dynamics and Materials Conference, Seattle, WA, April 2001, AIAA Paper No. 2001-1326. 
${ }^{46}$ Starnes, J. H., Jr., Newman, J. C., Jr., Harris, C. E., Young, R. D., Rose, C. A., and James, M. A., "Advances in Residual Strength Analyses from Laboratory Coupons to Structural Components," Proceedings of the ICAF 2001 International Committee on Aeronautical Fatigue 21 ${ }^{\text {st }}$ Symposium, Toulouse, France, June 2001.

47 Starnes, James H., Jr., and Rose, Cheryl A., "Stable Tearing and Buckling Response of Unstiffened Aluminum Shells with Long Cracks." Proceedings of the Second Joint NASA/FAA/DOD Conference on Aging Aircraft, Williamsburg, VA, August 31-September 3, 1998. NASA/CP-1999-208982/Part 1, pp. 610-626, January 1999.

48 Starnes, J. H., Jr., and Rose, C. A., "Nonlinear Response of Thin Cylindrical Shells with Longitudinal Cracks and Subjected to Internal Pressure and Axial Compression Loads," Proceedings of the 38th AIA/ASME/ASCE/AHS/ASC Structures, Structural Dynamics and Materials Conference, April 1997, AIAA Paper No. 97-1144, April 1997.

${ }^{49}$ Rose, C. A., Young, R. D., and Starnes, J. H., Jr., "The Nonlinear Response of Cracked Aluminum Shells Subjected to Combined Loads," Proceedings of the 42nd AIAA/ASME/ASCE/AHS/ASC Structures, Structural Dynamics and Materials Conference, Seattle, WA, April 2001, AIAA Paper No. 2001-1395.

50 Dawicke, D. S., "Residual Strength Predictions Using a Crack Tip Opening Angle Criterion," FAA-NASA Symposium on the Continued Airworthiness of Aircraft Structures, DOT/FAA/AR-97/2, Vol. II, July 1997, pp. 555566.

51 Seshadri, B. R., Newman, J. C., Jr., Dawicke, D. S., and Young, R. D., "Fracture Analysis of the FAA/NASA Wide Stiffened Panels," Proceedings of the FAA-NASA Symposium on the Continued Airworthiness of Aircraft Structures," DOT/FAA/AR-92/2, 1997, pp. 513-524.

52 Young, Richard D., Rouse, Marshall, Ambur, Damodar R., and Starnes, James H., Jr., "Residual Strength Pressure Tests and Nonlinear Analyses of Stringer- and Frame-Stiffened Aluminum Fuselage Panels with Longitudinal Cracks," Proceedings of the Second Joint NASA/FAA/DOD Conference on Aging Aircraft, Williamsburg, VA, August 31September 3, 1998. NASA/CP-1999-208982/Part 1, pp. 408-426, January 1999.

53 Ambur, Damodar R., Rouse, Marshall, Young, Richard D., and Perez-Ramos, Carlos, "Evaluation of an Aluminum Panel with Discrete-Source Damage and Subjected to Combined Loading Conditions," Proceedings or the 40th AIAA/ASME/ASCE/AHS/ASC Structures, Structural Dynamics, and Materials Conference, St. Louis, MO, April 1215, 1999. AIAA Paper AIAA-99-1439.

54 Dawicke, David S., Newman, James C., Jr., Starnes, James H., Jr., Rose, Cheryl A.; Young, Richard D. and Seshadri, B. R., "Residual Strength Analysis Methodology: Laboratory Coupons to Structural Components," Proceedings of the Third Joint FAA/DOD/NASA Conference on Aging Aircraft, Albuquerque, NM, September 20-23, 1999.

55 Dawicke, D. S., Newman, J. C., Jr., Sutton, M. A., and Amstutz, B. E., "Influence of Crack History on the Stable Tearing Behavior of a Thin-Sheet Material with Multiple Cracks," NASA CP 3274, FAA/NASA International Symposium on Advanced Structural Integrity Methods for Airframe Durability and Damage Tolerance, Part 1, 1994, pp. 193-212.

56 Shivakumar, K. N., and Newman, J. C., Jr., "ZIP3D - An Elastic-Plastic Finite-Element Analysis Program for Cracked Bodies," NASA TM-102753, 1990.

57 Dawicke, D.S., and Newman, J. C., Jr., "Residual Strength Predictions Using a Crack Tip Opening Angle Criterion," FAA-NASA Symposium on the Continued Airworthiness of Aircraft Structures, DOT/FAA.AR-97/2, Vol. II, July, 1997, pp. 555-566. 